\title{
Tetrapod Polymersomes
}

\author{
Jiangang Xiao, ${ }^{* * *}$ and Jianzhong Du $u^{\dagger, * * *}$
}

'Department of Orthopedics, Shanghai Tenth People’s Hospital, Tongji University School of Medicine, 301 Middle Yanchang Road, Shanghai 200072, China.

${ }^{*}$ Department of Polymeric Materials, School of Materials Science and Engineering, Key Laboratory of Advanced Civil Engineering Materials of Ministry of Education, Tongji University, 4800 Caoan Road, Shanghai 201804, China.

*Corresponding Author: jzdu@tongji.edu.cn

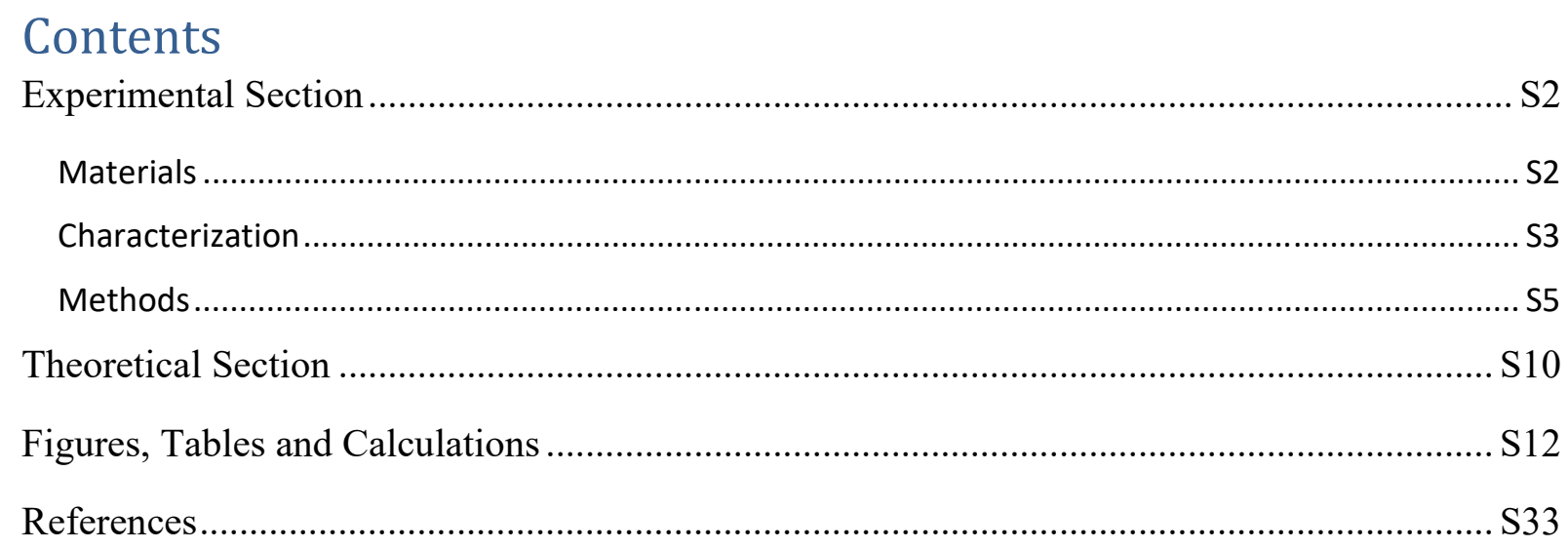




\section{Experimental Section}

\section{Materials}

Pinacol, 4-hydroxymethylphenylboronic acid, sodium sulfate anhydrous ( $\left.\mathrm{Na}_{2} \mathrm{SO}_{4}\right)$, 4(dimethylamino)pyridinium 4-toluenesulfonate (DPTS) were purchased from Innochem. Methacryloyl chloride, 4-dimethylaminopyridine, 2-hydroxyethyl methacrylate, carbonyldiimidazole, triethylamine (TEA), methacryloyl chloride, anhydrous magnesium sulfate $\left(\mathrm{MgSO}_{4}\right)$, sodium bicarbonate $\left(\mathrm{NaHCO}_{3}\right)$, dicyclohexylcarbodiimide (DCC, 96\%), 4dimethylaminopyridine (DMAP, 99\%), potassium carbonate $\left(\mathrm{K}_{2} \mathrm{CO}_{3}\right)$, 2-(diethylamino)ethyl methacrylate (DEA), Nile red and 2,2'-azobis(2-methylpropionitrile) (AIBN) were purchased from Aladdin Chemistry. Polyethylene oxide monomethylether $\left(\mathrm{PEO}_{113} ; M_{\mathrm{n}}=5000\right)$ was purchased from Alfa Aesar. Dialysis tube (8-14 kDa molecular weight cutoff), acetone, dichloromethane, tetrahydrofuran (THF), ethanol and other solvents were purchased from Sinopharm Chemical Reagent Co., Ltd. $\mathrm{CDCl}_{3}$ and DMSO- $d_{6}$ were purchased from J\&K Scientific Ltd. Chloroauric acid $\left(\mathrm{HAuCl}_{4}\right)$, and sodium borohydride $\left(\mathrm{NaBH}_{4}\right)$ were purchased from SigmaAldrich. 4',6-Diamidino-2-phenylindole (DAPI) was purchased from Beyotime Biotechnology (Shanghai, China). L02 cells (normal liver cells) were obtained from Institute of Biochemistry and Cell Biology, the Chinese Academy of Sciences (Shanghai, China). Roswell park memorial institute (RPMI), fetal bovine serum (FBS) and penicillin/streptomycin were purchased from Thermo Fisher Scientific Co., Ltd. (Shanghai, China). AIBN was recrystallized from methanol and stored at $4{ }^{\circ} \mathrm{C}$ prior to use. DEA was passed through an alumina B column to remove the inhibitor before usage. Dichloromethane was dried using calcium hydride and distilled. The chain transfer 
agent (CTA), 2-(dodecylthiocarbonothioylthio)-2-methylpropanoic acid (DDMAT) was synthesized according to previous protocols. ${ }^{1}$

\section{Characterization}

${ }^{1}$ H NMR. Spectra were recorded using a Bruker AV $400 \mathrm{MHz}$ spectrometer at room temperature using $\mathrm{CDCl}_{3}$ or DMSO- $d_{6}$ as the solvent.

Size Exclusion Chromatography (SEC). The molecular weights $\left(M_{\mathrm{n}}\right)$ and polydispersities $(\nexists)$ of the polymers were evaluated using a DMF SEC performed at $40{ }^{\circ} \mathrm{C}$ with two linear Styragel columns and an Agilent differential refractive index (RI) detector (1200 Infinity Series from Agilent Technologies, USA). High performance liquid chromatography (HPLC) grade DMF (0.05 M LiBr) was used as eluent with a constant flow rate of $0.8 \mathrm{~mL} \mathrm{~min}{ }^{-1}$. PEO was used as standard. Dynamic Light Scattering (DLS). Measurements were performed on a ZetaSizer Nano series instrument (Malvern S7 Instruments ZS 90) at a fixed scattering angle of $90^{\circ}$. Each reported measurement was conducted for three runs and the $D_{\mathrm{h}}$ and PD were calculated by the Z-averaged value.

Transmission Electron Microscopy (TEM). TEM images were obtained using a JEM-2100 electron microscope equipped with a Gatan $1 \mathrm{k} \times 1 \mathrm{k}$ pixel digital camera operating at an acceleration voltage of $200 \mathrm{kV}$. All the solutions were diluted at ambient temperature. Each sample $(8.0 \mu \mathrm{L})$ was then dropwise added onto the carbon-coated copper grid and dried under ambient conditions. The intermediate morphologies were obtained by adding $20 \mu \mathrm{L}$ of the intermediate 
solution to $2.0 \mathrm{~mL}$ of $\mathrm{DI}$ water during the self-assembly process to 'quench' the morphologies before preparing the TEM samples.

Scanning Electron Microscopy (SEM). SEM samples were prepared as follows: a drop of solution $(8.0 \mu \mathrm{L})$ was spread on each silicon wafer and left at room temperature to dry. Intermediate morphologies were quenched by adding $20 \mu \mathrm{L}$ of the intermediate solution to $2.0 \mathrm{~mL}$ of DI water during the self-assembly process before preparing the SEM samples. Samples were coated with platinum and viewed by a FEI Quanta 250 FEG electron microscope (USA) or Nova NanoSEM 450 electron microscope (USA). The images were recorded using a digital camera.

UV-Vis Spectroscopy. The UV-Vis spectroscopy was used to measure the optical density (OD) of the solution during the self-assembly process to get the turbidity value via a UV759S UV-vis spectrophotometer (Shanghai Precision \& Scientific Instrument Co., Ltd.). UV-Vis was used to measure the samples turbidity (a.k.a. transmittance) at $650 \mathrm{~nm}$.

Ultrasound Probe. Ultrasound probe (FS-250N $\Phi 6 \mathrm{~mm}$ ) was used to test the thermodynamic stability of the nanostructures at $25^{\circ} \mathrm{C}$, using a water bath. The ultrasound probe is purchased from Shanghai Sonxi Ultrasonic Instrument Co., LTD with frequency $20 \mathrm{kHz}$ (The power is set as 45 W).

Differential Scanning Calorimetry (DSC). A Q100 DSC (TA Instruments, USA) was used to record the $T_{\mathrm{g}}$ of the hydrophobic segment of block copolymers. The samples were kept for $3 \mathrm{~min}$ at $-40{ }^{\circ} \mathrm{C}$ and heated afterwards a rate of $20^{\circ} \mathrm{C} \min ^{-1}$ to $160{ }^{\circ} \mathrm{C}$.

Confocal Laser Scanning Microscopy (CLSM). CLSM (Nikon, C2 Plus, Japan) was used to track the cellular internalization of normal liver L02 cells incubated with the spherical micelles form P1 and the tetrapod polymersomes from P3 labelled with Nile red. 


\section{Methods}

Synthesis of 4-(Hydroxymethyl)phenylboronic Acid Pinacol Ester. Pinacol (4.67 g, 39.5 mmol), 4-(hydroxymethyl)phenylboronic acid (5.00 g, $32.9 \mathrm{mmol})$, sodium sulfate (5.00 g), and dried THF $(60.0 \mathrm{~mL})$ were charged into a $150 \mathrm{~mL}$ of two-necked flask and stirred for $12 \mathrm{~h}$ under nitrogen at $35{ }^{\circ} \mathrm{C}$. The mixture was filtered and concentrated, and redissolved in $60 \mathrm{~mL}$ of dichloromethane, followed by washing with deionized water $(3 \times 100 \mathrm{~mL})$. The organic phase was dried over $\mathrm{MgSO}_{4}$, filtered, and concentrated to afford 4-(hydroxymethyl)phenylboronic acid pinacol ester (6.11 g, yield: $79 \%) .{ }^{1} \mathrm{H}$ NMR spectrum is provided in Figure S3.

Synthesis of 4-(4,4,5,5-Tetramethyl-1,3,2-dioxaborolan-2-yl)benzyl Methacrylate (TBA). 4-(Hydroxymethyl)phenylboronic acid pinacol ester (5.00 g, $21.4 \mathrm{mmol})$ was dissolved in anhydrous dichloromethane $(40 \mathrm{~mL})$, followed by addition of TEA $(2.60 \mathrm{~g}, 25.7 \mathrm{mmol})$. After cooling to $\sim 0{ }^{\circ} \mathrm{C}$, methacryloyl chloride $(2.30 \mathrm{~g}, 22.0 \mathrm{mmol})$ in $5.0 \mathrm{~mL}$ of dried dichloromethane was added dropwise within $1 \mathrm{~h}$. Then, the reaction mixture was warmed to room temperature, stirred for $24 \mathrm{~h}$ and filtered. The filtrate was washed three times with brine. After drying over $\mathrm{MgSO}_{4}$, the organic solution was concentrated and purified by silica column chromatography using petroleum ether and ethyl acetate $(\mathrm{v} / \mathrm{v}=30 / 1)$ as the eluent. 4-(4,4,5,5-Tetramethyl-1,3,2dioxaborolan-2-yl)benzyl methacrylate (TBA) was obtained as colorless liquid (4.32 g, yield: $66 \%) .{ }^{1} \mathrm{H}$ NMR spectrum is provided in Figure S4.

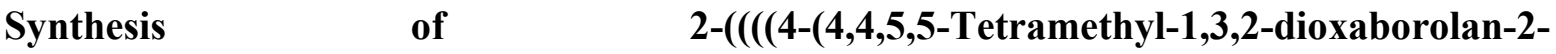

yl)benzyl)oxy)carbonyl)oxy)ethyl Methacrylate (TBEA). 4-(Hydroxymethyl)phenylboronic acid pinacol ester $(5.00 \mathrm{~g}, 21.4 \mathrm{mmol})$ was dissolved in $20 \mathrm{~mL}$ of anhydrous dichloromethane, followed by addition of carbonyldiimidazole $(5.21 \mathrm{~g}, 32.1 \mathrm{mmol})$. After $8 \mathrm{~h}$, the reaction mixture was diluted with $100 \mathrm{~mL}$ of dichloromethane and washed with deionized water $(3 \times 70 \mathrm{~mL})$. The 
organic phase was dried over anhydrous sodium sulfate, filtered, and concentrated to afford white solid (6.11 g, yield: 87.3\%). Then, the white solid (5.00 g, $15.2 \mathrm{mmol}$ ), 2-hydroxyethyl methacrylate $(2.37 \mathrm{~g}, 18.2 \mathrm{mmol})$, and DMAP $(0.150 \mathrm{mmol}, 18.5 \mathrm{mg})$ were dissolved in anhydrous dichloromethane $(80 \mathrm{~mL})$ and stirred for $12 \mathrm{~h}$ at $30{ }^{\circ} \mathrm{C}$. Then the solvent was removed in vacuo and the sample was purified by silica column chromatography using petroleum ether and ethyl acetate $(\mathrm{v} / \mathrm{v}=4 / 1)$ as the eluent, and a white solid (TBEA) was finally obtained $(4.60 \mathrm{~g}, 71.1 \%)$. ${ }^{1} \mathrm{H}$ NMR spectrum is provided in Figure S5.

\section{Syntheses of Block Copolymer (P3), P1, P2, P4, P5, P6 and Other Polymers by RAFT}

Polymerization. The synthetic procedure of poly(ethylene oxide)-block-poly[4-(4,4,5,5tetramethyl-1,3,2-dioxaborolan-2-yl)benzyl methacrylate-stat-2-(diethylamino)ethyl methacrylate] [PEO113-b-P(TBA61-stat-DEA23)] is as follows: PEG-based RAFT agent (106 mg, $0.0198 \mathrm{mmol})$, AIBN (0.46 mg, $0.0028 \mathrm{mmol})$, PTBA monomer (483.5 mg, $1.600 \mathrm{mmol})$, DEA monomer $(111.2 \mathrm{mg}, 0.6002 \mathrm{mmol})$ and 1,4-dioxane $(2.4 \mathrm{~mL})$ were charged into a $5.0 \mathrm{~mL}$ of Schlenk tube with a stirrer bar. The flask was subsequently purged with argon 30 min and immerged into the oil bath at $80{ }^{\circ} \mathrm{C}$. After $24 \mathrm{~h}$, the reaction was terminated by cooling to RT and exposure to air. After removing the 1,4-dioxane by rotatory evaporation, the crude product was dissolved into dichloromethane and followed by precipitation in $n$-hexane for three times ( 444.3 mg, yield: 63\%). P1, P2, P4, P5, P6 and the other polymers were synthesized using the same method while varying the amount of monomer subunits. ${ }^{1} \mathrm{H}$ NMR spectra are provided in Figure S8-Figure S13.

Self-Assembly of P1, P2, P3, P4, P5 and P6. Typically, $10 \mathrm{mg}$ of copolymer was dissolved in $5.0 \mathrm{~mL}$ of DMF at an initial concentration of $2.0 \mathrm{mg} / \mathrm{mL}$. DI water $(10 \mathrm{~mL})$ was then added dropwise to the solution under vigorous stirring to get $C_{\mathrm{w}}$ up to $67 \%$. The residual organic solvent 
was removed subsequently by dialyzing against deionized water $(7 \times 1000 \mathrm{~mL})$ for $48 \mathrm{~h}$. Additionally, P3 was self-assembled in the same manner using THF instead. The final $\mathrm{pH}$ values of the nanoparticles from P1 to P6 (produces with DMF as organic solvent) were 5.52, 6.28, 6.45, 6.91, 6.97 and 6.94, respectively. The final $\mathrm{pH}$ value of the peapods from P3 with THF as organic solvent was 7.01 .

Turbidity Studies during Self-Assembly Process. PEO $113-b-\mathrm{P}\left(\mathrm{TBA}_{61}-\right.$ stat-DEA23) block copolymer $(10.0 \mathrm{mg})$ was dissolved in $5.0 \mathrm{~mL}$ of DMF. $10 \mathrm{~mL}$ of DI water was added dropwise into the solution under wield stirring. When the DI water content was $6 \%, 8 \%, 10 \%, 12 \%, \ldots$, until $68 \%$, the dispersion was stirred for additional several minutes once the desired $C_{\mathrm{w}}$ was achieved. Then, UV-Vis measurements were performed at a wavelength range of $400-800 \mathrm{~nm}$. The transmittance $(\mathrm{T})$ data at $650 \mathrm{~nm}$ were used for the turbidity analysis. The turbidity data were obtained from $\mathrm{T}$ data, i.e., $100-\mathrm{T} \%$. DMF was used as the reference for all the measurements. The turbidity studies with THF as organic solvent was conducted with a similar way.

DLS, TEM and SEM Studies of the P3 and P5 Solutions with DMF as Organic Solvent, and the P3 Solution with THF as Organic Solvent During Self-assembly. $\mathrm{PEO}_{113}-b-\mathrm{P}\left(\mathrm{TBA}_{61}-\right.$ stat-DEA 23$)$ block copolymer $(10.0 \mathrm{mg})$ was dissolved in $5.0 \mathrm{~mL}$ of DMF. DI water was added dropwise into the solution under gentle stirring. When the DI water content of the solution was $10 \%, 14 \%, 18 \%$, etc., small amount of the solution was added to $2.0 \mathrm{~mL}$ of DI water and the concentration of the solution was kept constant. The $C_{\mathrm{w}}$ of $100 \%$ was achieved by dialyzing the solution with a $C_{\mathrm{w}}$ of $67 \%$ against deionized water $(15 \mathrm{~mL}$ of solution against $1000 \mathrm{~mL}$ of deionized water) for $48 \mathrm{~h}$ and exchanging water every $8 \mathrm{~h}$. The $\mathrm{pH}$ value of the final solution was 6.45 The hydrodynamic diameters $\left(D_{\mathrm{h}}\right)$ and polydispersity $(\mathrm{PD})$ of the self-assemblies were then obtained by DLS measurements. The same samples were used for TEM and SEM analysis. The 
self-assembly process of P5 with DMF and P3 with THF as organic solvent was studied in the same manner. The solid contents of the initial $\left(C_{\mathrm{w}}=0\right)$ and final $\left(C_{\mathrm{w}}=100 \%\right)$ solutions are $0.21 \%$ $\mathrm{w} / \mathrm{w}$ and $0.06 \% \mathrm{w} / \mathrm{w}$, respectively.

Preparation of Gold-Decorated Tetrapod Polymersomes (AuNP@TP). In situ immobilization of AuNPs in the membrane of tetrapod polymersomes was conducted as follows. An aqueous $\mathrm{HAuCl}_{4}$ solution $(1.0 \mathrm{mg} / \mathrm{mL})$ was added into the tetrapod polymersome dispersion at an Au:DEA molar ratio of 1:2 and 1:1 was used to prepare AuNP@TP 1 and AuNP@TP 2. After stirring the mixture for $1 \mathrm{~h}$, a $\mathrm{NaBH}_{4}$ solution (prepared on site, 1:1.2 molar ratio relative to the amount of $\mathrm{HAuCl}_{4}$ ) to achieve the in situ reduction of AuNPs on the membrane of tetrapod polymersomes. The tetrapod polymersome solution turned dark red immediately. Then, the AuNP@TP 1 and AuNP@TP 2 solutions were dialyzed against DI water to remove free AuNPs and excessive $\mathrm{NaBH}_{4}$. Finally, AuNP@TP 1 and AuNP@TP 2 were prepared.

\section{Preparation of Nile Red-Labelled Tetrapod Polymersomes from P3 (NR-polymersomes)} and Micelles from P1 (NR-micelles). A Nile red solution $(10 \mu \mathrm{g} / \mathrm{mL})$ was prepared in DMF. P3 or P1 (10.0 mg) was dissolved in 5.0 mL of DMF, subsequently $50 \mu \mathrm{L}$ Nile red solution $(10 \mu \mathrm{g} / \mathrm{mL})$ was added to this dispersion, then distilled water $(10.0 \mathrm{~mL})$ was added dropwise into the solution under continuous stirring. Finally, the solution was dialyzed against deionized water $(7 \times 1000 \mathrm{~mL})$ for $48 \mathrm{~h}$. All the above experiments were carried in a dark room.

Confocal Laser Scanning Microscopy (CLSM) to Observe Cellular Internalization. L02 cells were cultured with roswell park memorial institute (RPMI) supplemented with $10 \%$ fetal bovine serum (FBS) and $1 \%$ penicillin/streptomycin at $37^{\circ} \mathrm{C}$ and a $5 \% \mathrm{CO}_{2}$ atmosphere. $\mathrm{L} 02$ cells were seeded on coverslips in 12 -well plates at a density of $1 \times 10^{5}$ cells per well and incubated for $12 \mathrm{~h}$. The media were replaced with $500 \mu \mathrm{L}$ of fresh medium containing $10 \%$ FBS, followed by 
$50 \mu \mathrm{L}$ of NR-micelles or NR-polymersomes and incubated for $3 \mathrm{~h}$. After incubation, the cells were washed with PBS for three times and fixed with $4 \%$ paraformaldehyde for $10 \mathrm{~min}$ at room temperature. Nuclei were stained with DAPI at the concentration of $1.0 \mu \mathrm{g} / \mathrm{mL}$ for $10 \mathrm{~min}$. Finally, the coverslips were taken out car enclosed with antifade mounting medium, the samples were subsequently observed by CLSM. 


\section{Theoretical Section}

Fusion of Vesicles. Dissipative particle dynamics (DPD) simulations suggest that vesicle fusion occurs spontaneously when two criteria are satisfied: (a) Adhesive collision occurs between vesicles; (b) the membrane bending energy $\left(E_{\mathrm{b}}\right)$ is the dominating energetic barrier of fusion, and the membrane tension should overcome this energetic barrier for vesicles to fuse. ${ }^{2,3}$ The membrane bending energy is defined in eq 1

$$
E_{\mathrm{b}}=\sigma \Delta A+\oint \frac{\kappa}{2} C^{2} \mathrm{~d} A
$$

Where $\sigma, \Delta A, \kappa, C$ are membrane tension, ${ }^{4}$ change in membrane surface area, membrane bending rigidity, ${ }^{5}$ and local membrane curvature, respectively. ${ }^{2,6,7}$ This equation suggests that a buildup of membrane tension increases its bending energy; the release of membrane tension can significantly drive vesicle fusion as it reduces the overall $E_{\mathrm{b}}$ of the system. Indeed, this tension can be released through a range of pathways, including vesicle fusion, hemifusion, membrane deformation, or

membrane rupture. ${ }^{3,8-11}$ In contrast, the pathway to minimize $E_{\mathrm{b}}$ by reducing $\Delta A$ or $C$ seems limited as it involves membrane rearrangement processes. Similarly, the way to minimize $E_{\mathrm{b}}$ by reducing $\kappa$ is limited as it relates to the change in hydrophobic membrane thickness, ${ }^{5}$ or the membrane's amphiphilic constituents. $^{12}$

An increase in water content $\left(C_{\mathrm{w}}\right)$ can increase membrane tension by squeezing organic solvent 'plasticizer' out of the membrane of vesicles. ${ }^{13}$ Also, an increase in degree of polymerization (DP) of hydrophobic block can enhance the hydrophobicity and thickness of a vesicle membrane, thus increase membrane tension. ${ }^{5}$ Indeed, DPD simulations on fusion of rod-coil polymersomes suggest that membrane tension scales with the rod block DP. ${ }^{14}$ If a vesicle membrane becomes "charged" with high tension, fusion can be triggered upon releasing this tension. 
Fusion of Vesicles at Low Solid Content. Vesicle fusion usually occurs at relatively high solid content due to more particle-particle adhesion than that in a dilute solution. ${ }^{2,10,11,15}$ Charged coronas are also regarded as disfavoured for such adhesion due to particle-particle repulsion. ${ }^{2,16}$ Therefore, fusion of charged vesicles at low solid content is a complicated challenge. 
Figures, Tables and Calculations

(A)

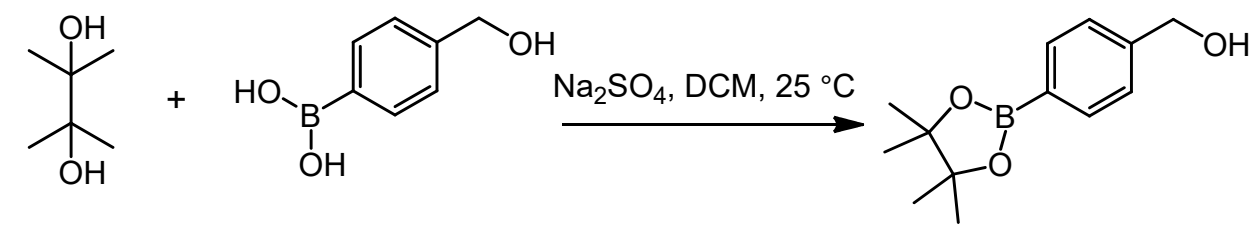<smiles>CC1(C)OB(c2ccc(CO)cc2)OC1(C)C</smiles><smiles>C=C(C)C(=O)Cl</smiles><smiles>C=C(C)C(=O)OCc1ccc(B2OC(C)(C)C(C)(C)O2)cc1</smiles>

(B)<smiles>CC1(C)OB(c2ccc(CO)cc2)OC1(C)C</smiles><smiles>C=C(C)C(=O)OCCOC(=O)OCc1ccc(B2OC(C)(C)C(C)(C)O2)cc1</smiles>

(C)

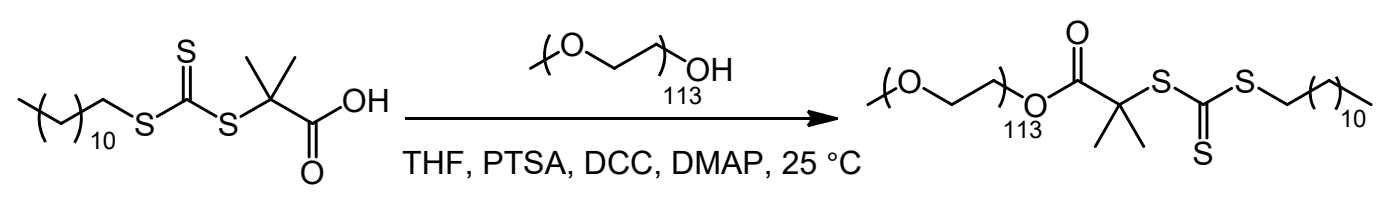
PEO $_{113}$-DDMAT

Figure S1. Syntheses of (A) TBA monomer, (B) TBEA monomer and (C) PEO 113 -DDMAT RAFT agent. 


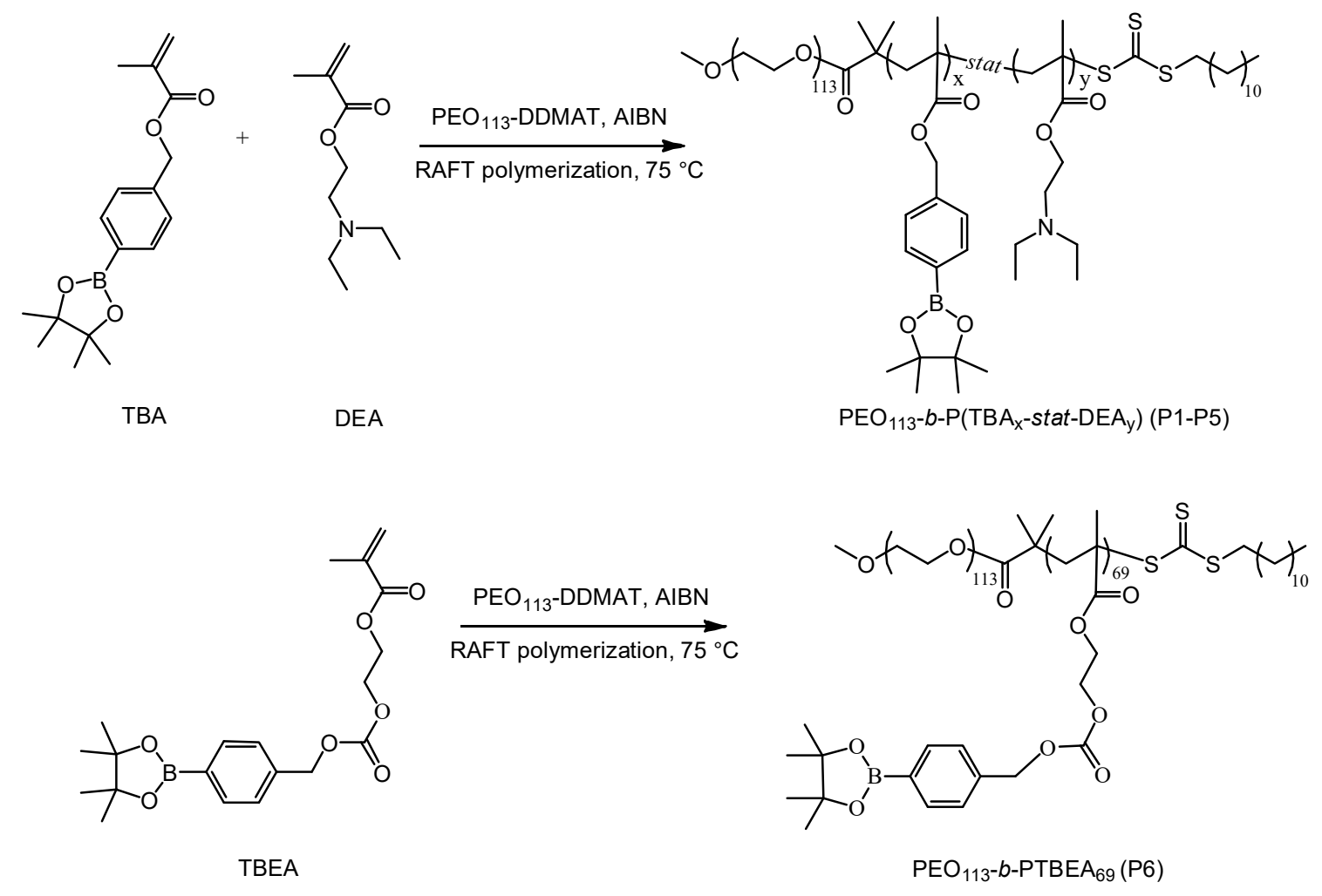

Figure S2. Syntheses of block copolymers P1-P6 via a RAFT process.

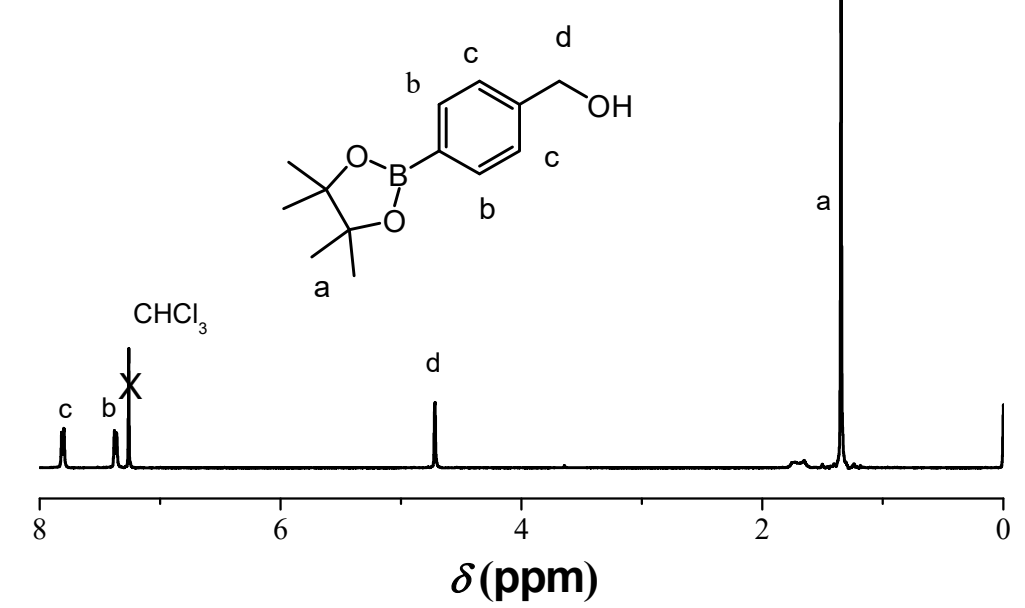

Figure S3. ${ }^{1} \mathrm{H}$ NMR spectrum of 4-(hydroxymethyl)phenylboronic acid pinacol ester in $\mathrm{CDCl}_{3}$. 


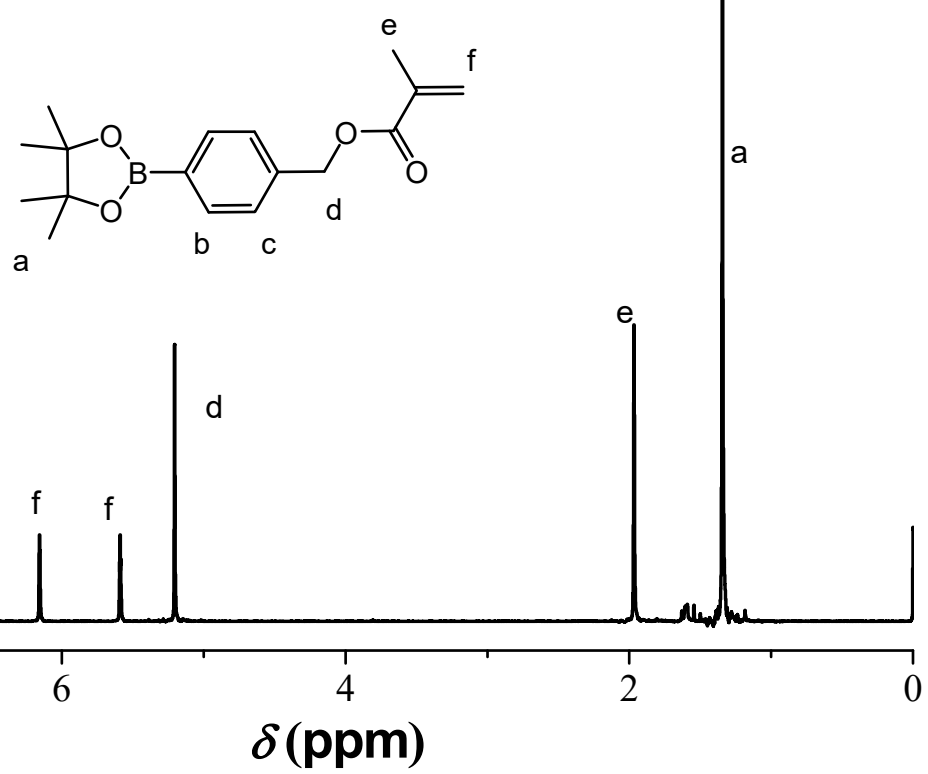

Figure S4. ${ }^{1} \mathrm{H}$ NMR spectrum of TBA monomer in $\mathrm{CDCl}_{3}$.
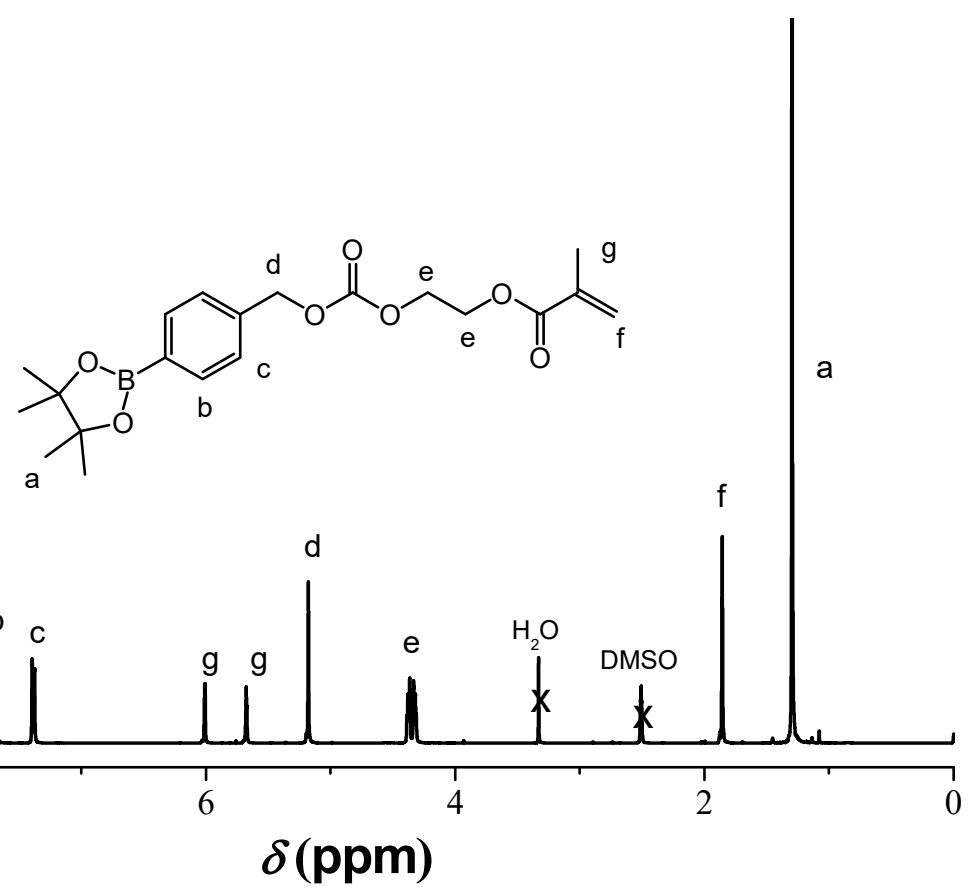

Figure S5. ${ }^{1} \mathrm{H}$ NMR spectrum of TBEA monomer in DMSO- $d 6$. 


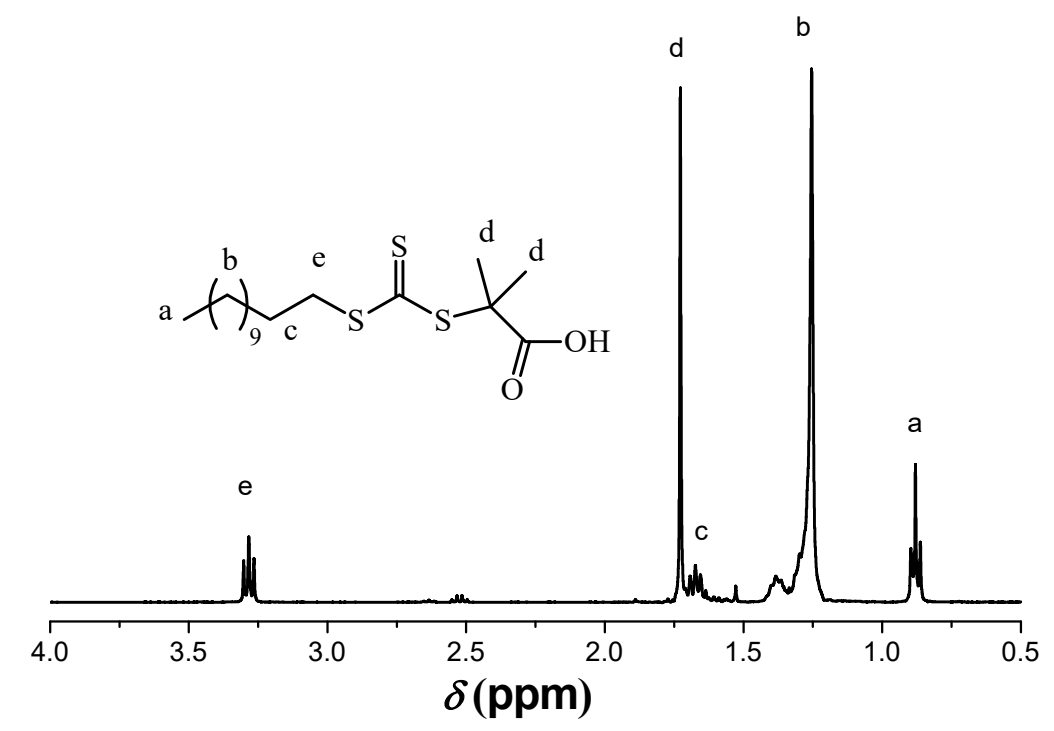

Figure S6. ${ }^{1} \mathrm{H}$ NMR spectrum of DDMAT in $\mathrm{CDCl}_{3}$.

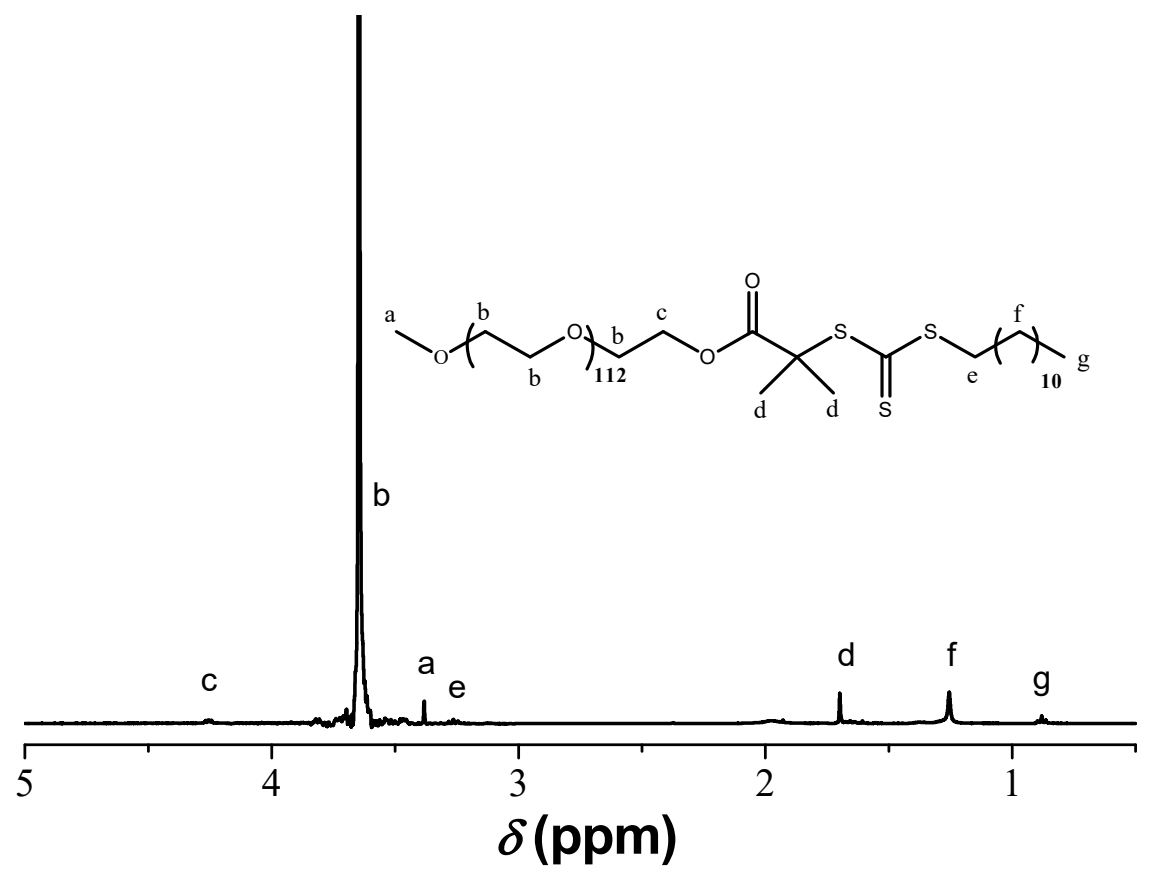

Figure S7. ${ }^{1} \mathrm{H}$ NMR spectrum of $\mathrm{PEO}_{113}-\mathrm{DDMAT}$ in $\mathrm{CDCl}_{3}$. 


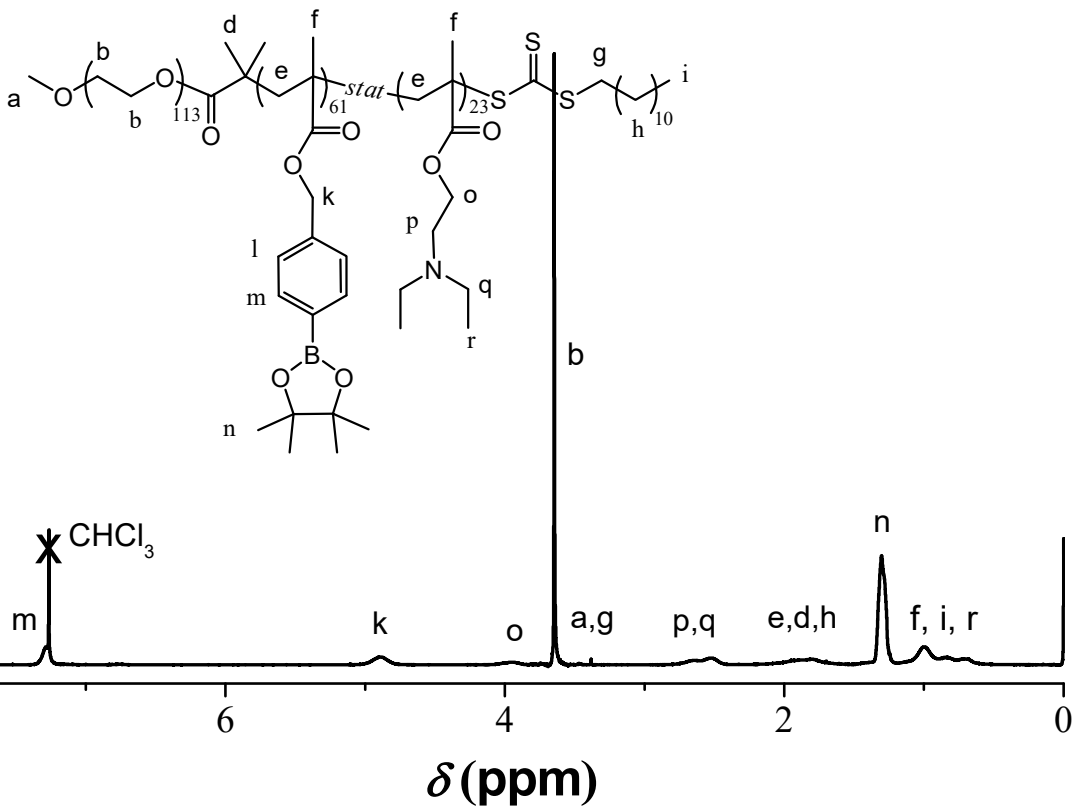

Figure S8. ${ }^{1} \mathrm{H}$ NMR spectrum of $\mathrm{PEO}_{113}-b$-P(TBA41-stat-DEA 23$)(\mathrm{P} 3)$ block copolymer in $\mathrm{CDCl}_{3}$.
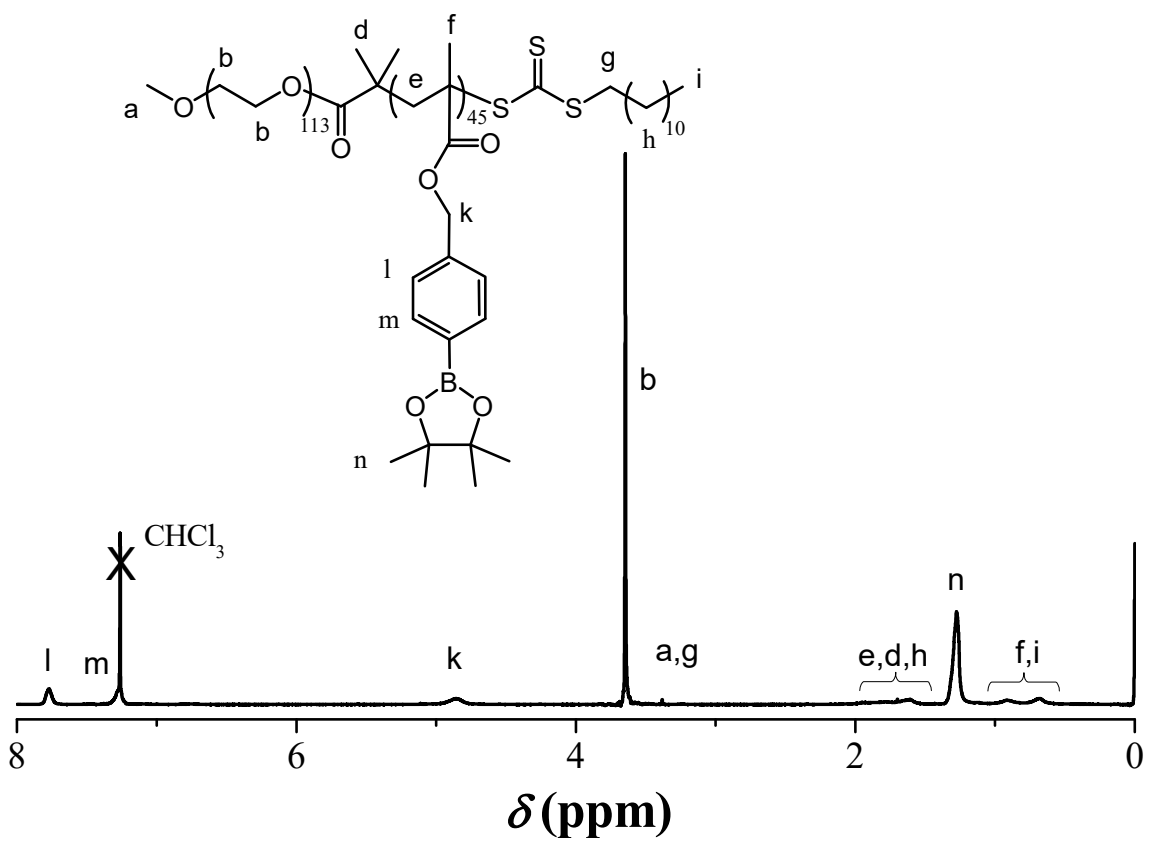

Figure S9. ${ }^{1} \mathrm{H}$ NMR spectrum of $\mathrm{PEO}_{113}-b-\mathrm{PTBA}_{45}(\mathrm{P} 1)$ block copolymer in $\mathrm{CDCl}_{3}$. 


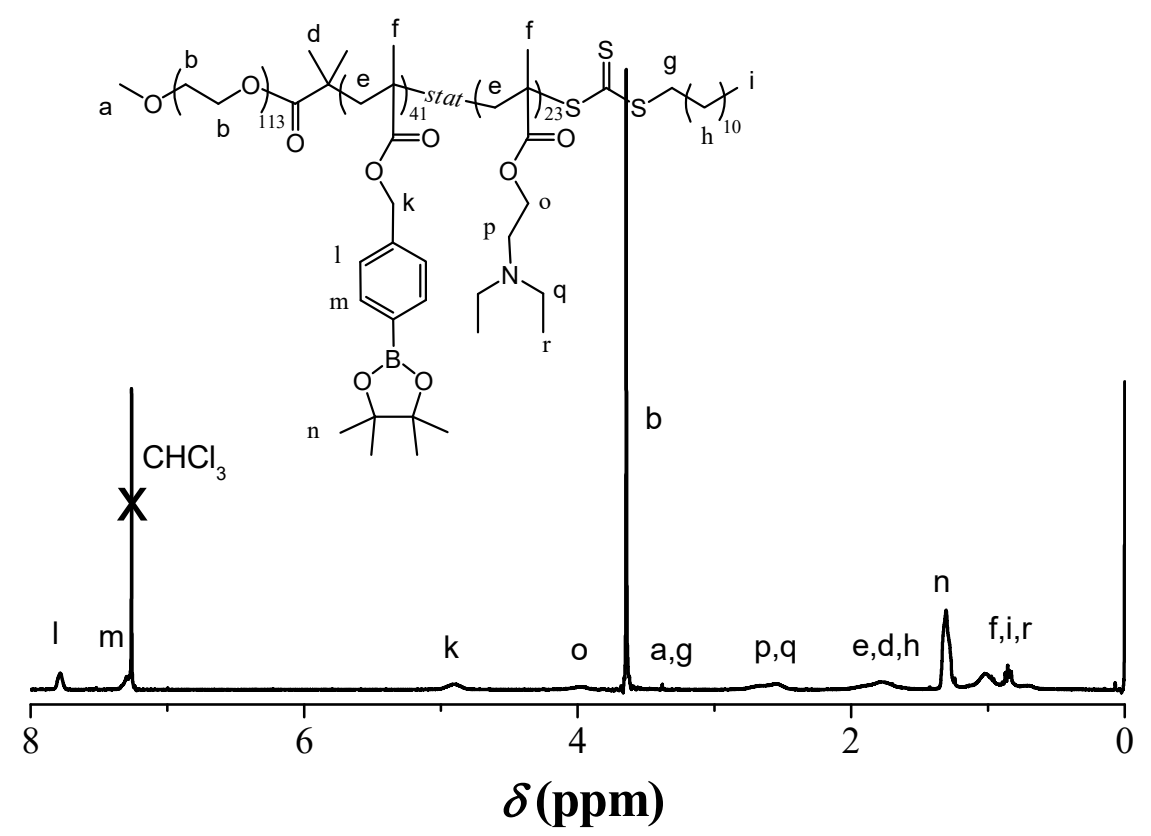

Figure S10. ${ }^{1} \mathrm{H}$ NMR spectrum of $\mathrm{PEO}_{113}-b-\mathrm{P}\left(\mathrm{TBA}_{41}-\right.$ stat-DEA 23$)(\mathrm{P} 2)$ block copolymer in $\mathrm{CDCl}_{3}$.

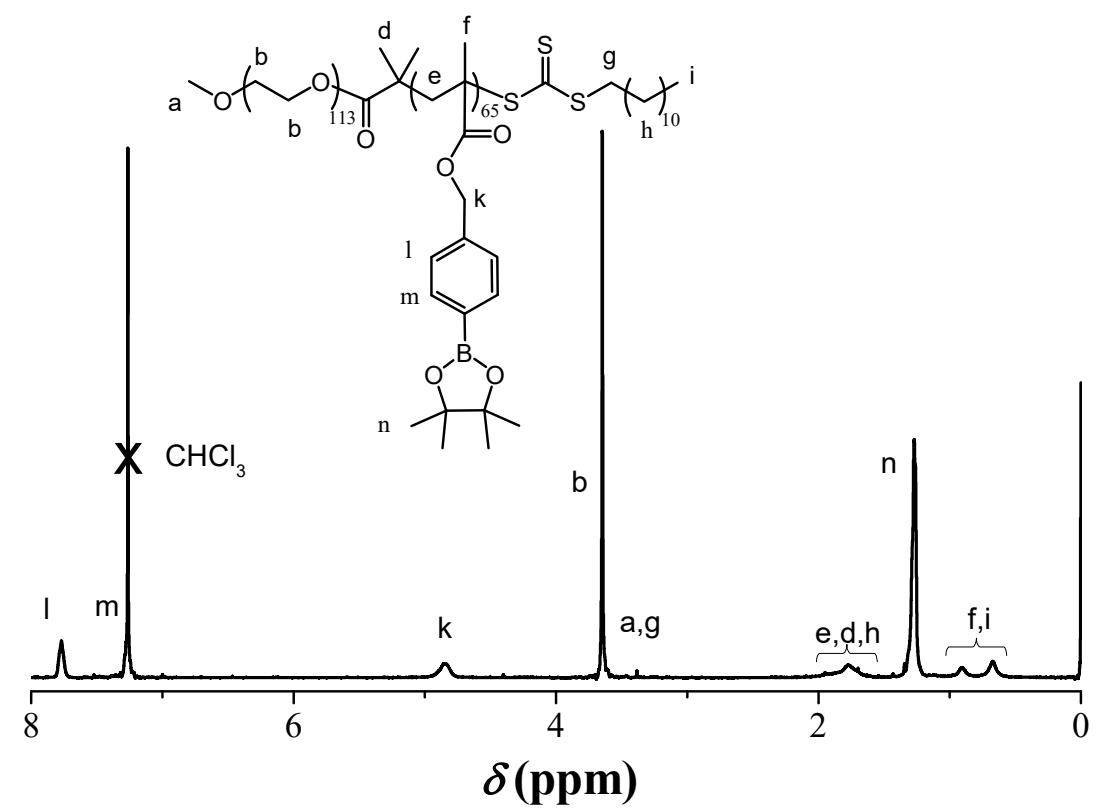

Figure S11. ${ }^{1} \mathrm{H}$ NMR spectrum of $\mathrm{PEO}_{113}-b-\mathrm{PTBA}_{65}(\mathrm{P} 4)$ block copolymer in $\mathrm{CDCl}_{3}$. 


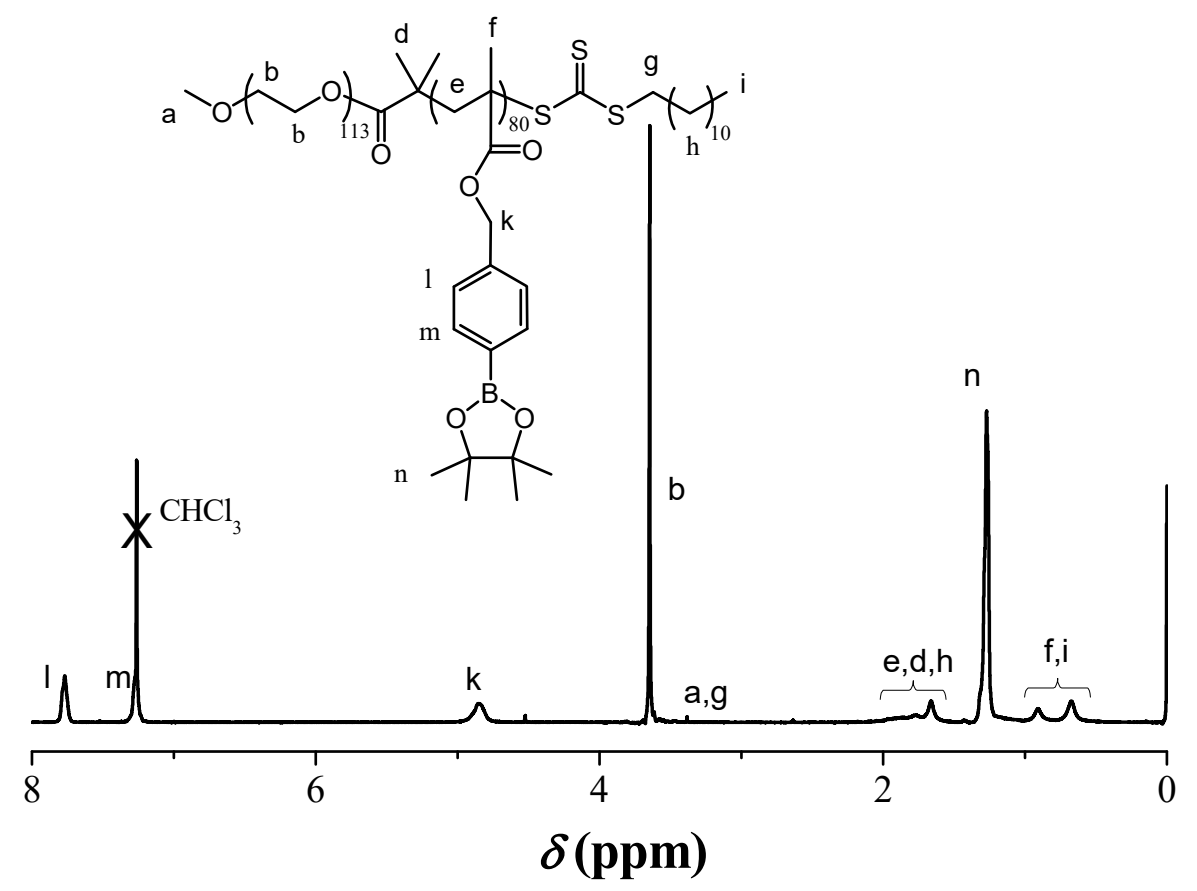

Figure S12. ${ }^{1} \mathrm{H}$ NMR spectrum of $\mathrm{PEO}_{113}-b-\mathrm{PTBA} 80$ (P5) block copolymer in $\mathrm{CDCl}_{3}$.

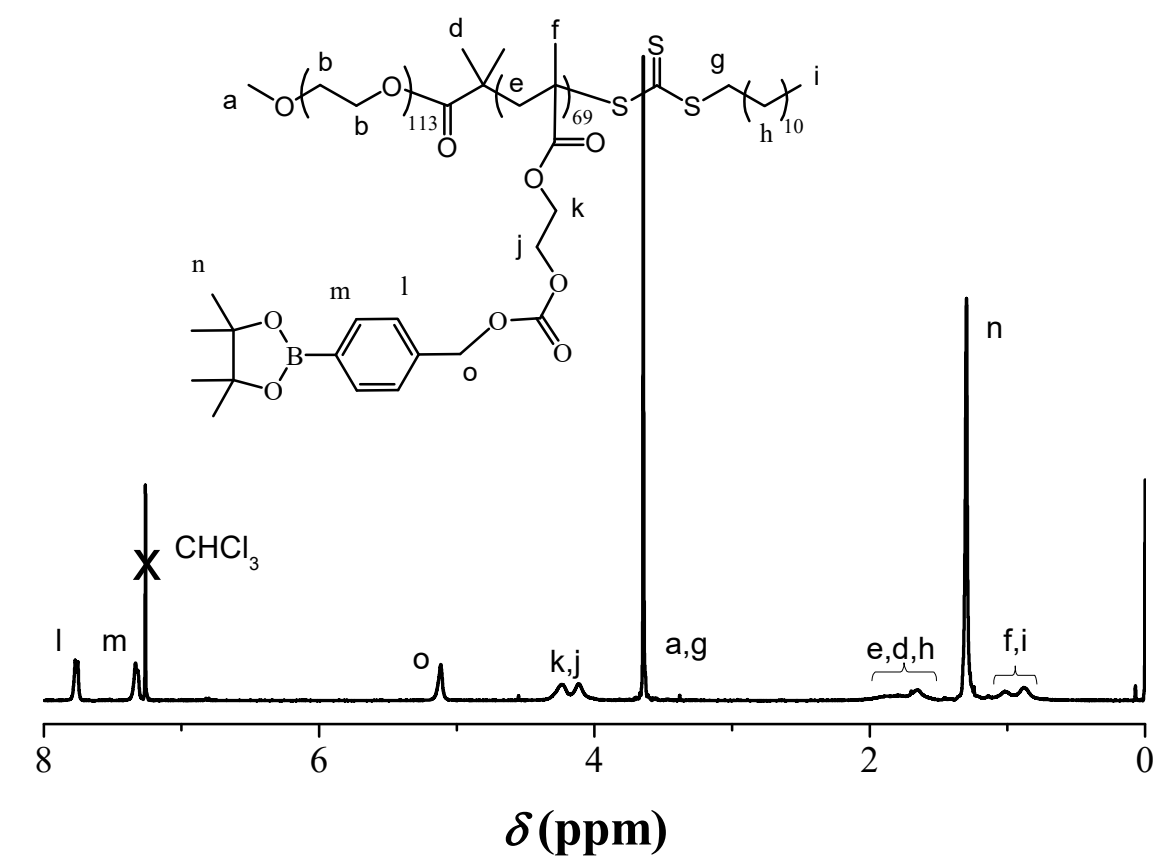

Figure S13. ${ }^{1} \mathrm{H}$ NMR spectrum of $\mathrm{PEO}_{113}-b-\mathrm{PTBEA}_{69}$ (P6) block copolymer in $\mathrm{CDCl}_{3}$. 

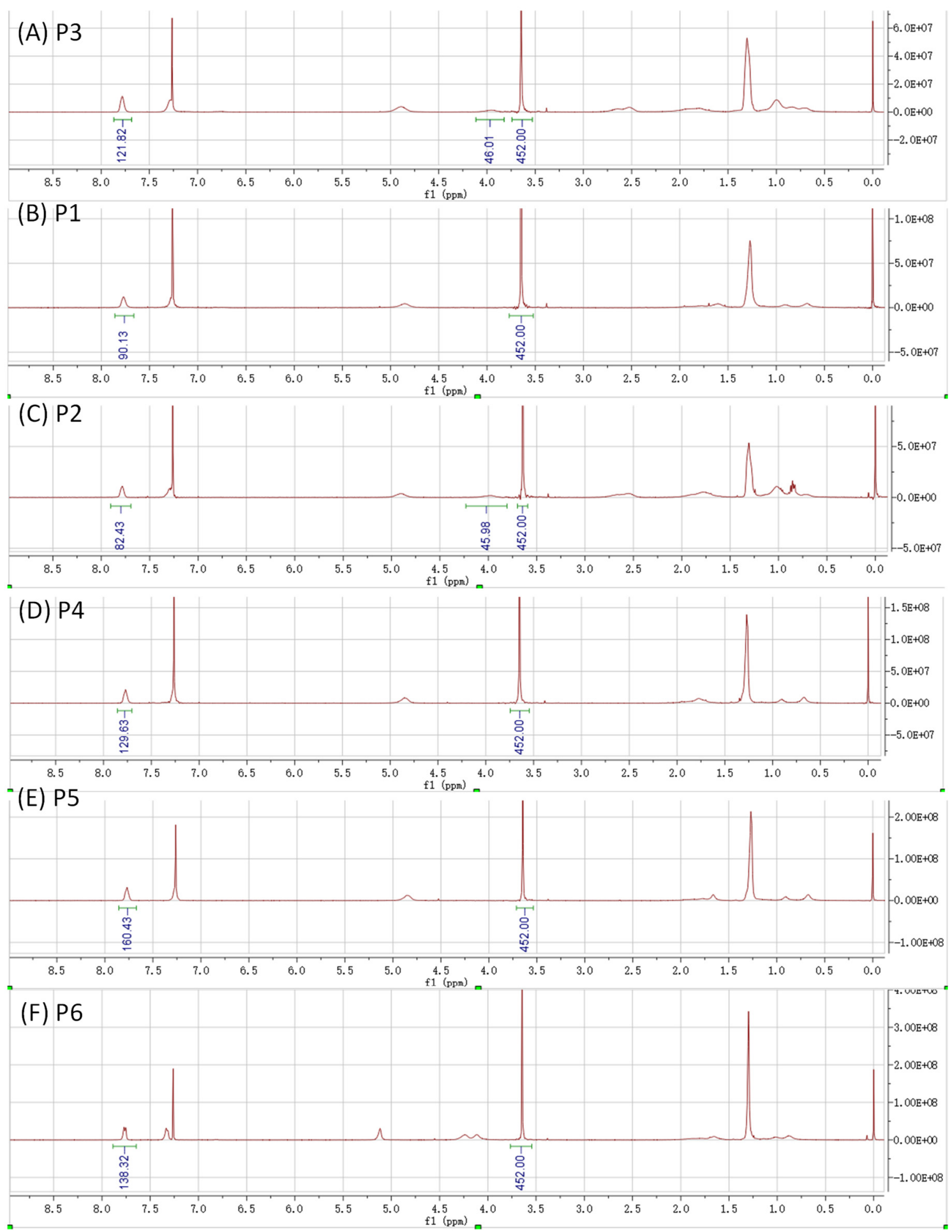

Figure S14. ${ }^{1} \mathrm{H}$ NMR spectra with the integral values of (A) P3, (B) P1, (C) P2, (D) P4, (E) P5 and (F) P6. 

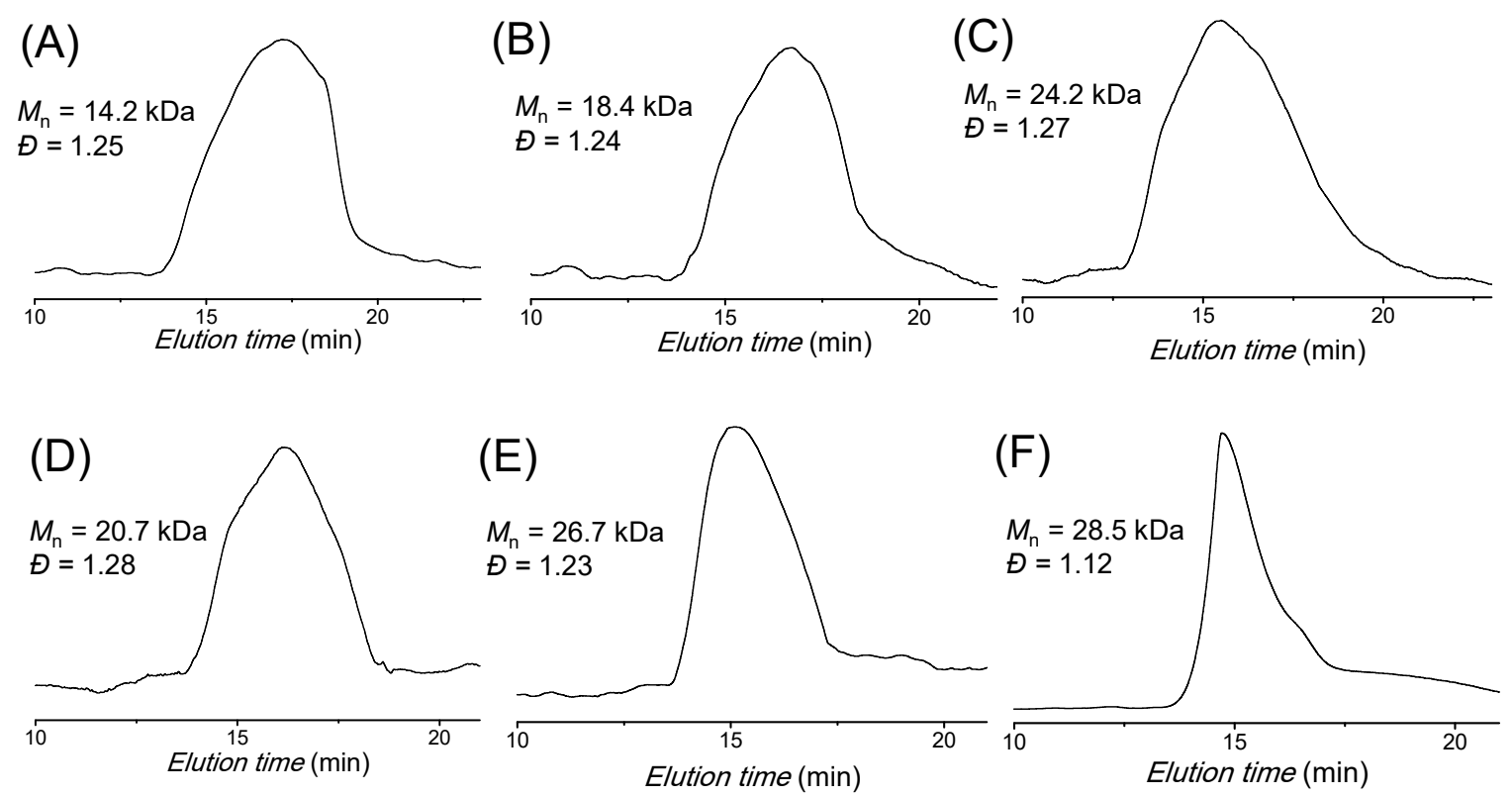

Figure S15. SEC analyses of block copolymers: (A) P1, (B) P2, (C) P3, (D) P4, (E) P5 and (F) P6.

\section{Calculation of the Degree of Polymerization of P3, P1, P2, P4, P5 and P6.}

Table S1. The Peak Areas and with Corresponding Calculated the Degree of Polymerization (DP) of TBA $(x)$ and DEA $(y)$ in $\mathrm{PEO}_{113}-b-\mathrm{P}\left(\mathrm{TBA}_{x}-\right.$ stat-DEA $\left.y\right)(\mathrm{P} 3)^{\dagger}$

\begin{tabular}{cccc}
\hline Peak & $\mathrm{A}_{\mathrm{b}}$ & $\mathrm{A}_{\mathrm{l}}$ & $\mathrm{A}_{\mathrm{o}}$ \\
\hline Number of $\mathrm{H}$ & 452 & $2 x$ & $2 y$ \\
\hline Peak area & $452 \mathrm{a}$ & $121.8 \mathrm{a}$ & $46.1 \mathrm{a}$
\end{tabular}

${ }^{\dagger}$ In Table S1, $A_{b}, \overline{A_{l}}$ and $A_{o}$ are the integral areas of peaks b, 1 and o in Figure S8 (the ppm values of $b, 1$ and $o$ are $3.65,7.78$ and 3.95, respectively). When the area of peak $b\left(\mathrm{~A}_{b}\right)$ is set to be 452a, the peak areas of 1 and o are 121.8a and 46.1a, respectively. Since the peak areas are directly proportional to the number of $\mathrm{H}$, the DP can be calculated according to eq 2

$$
\frac{452}{452 \mathrm{a}}=\frac{2 \mathrm{x}}{121.8 \mathrm{a}}=\frac{2 \mathrm{y}}{46.1 \mathrm{a}}
$$

Therefore, $x$ is calculated to be 61 , and $y$ is 23 , then the block copolymer is $\mathrm{PEO}_{113}-b-\mathrm{P}\left(\mathrm{TBA}_{61}-\right.$ stat-DEA23). 
Following a similar procedure, P1, P2, P4, P5 and P6 in Figure S9-Figure S13 are: PEO113-bPTBA45, PEO $113-b$-P(TBA41-stat-DEA23), PEO $113-b-\mathrm{PTBA}_{65}, \mathrm{PEO}_{113}-b-\mathrm{PTBA}_{80}$ and PEO $113-b-$ PTBEA69. The corresponding integral values are shown in Figure S14.

\section{Calculation of Solubility Parameter Values}

The solubility parameter $(\delta)$ of the $\mathrm{DMF} /$ water or $\mathrm{THF} /$ water solvent mixtures is calculated according to eq 3

$$
\delta_{\text {mix }}=\delta_{1} \varphi_{1}+\delta_{2} \varphi_{2}
$$

Here, $\delta_{1}, \delta_{2}$ and $\varphi_{1}, \varphi_{2}$ represent the solubility parameter values and volume fractions of the solvent, $\delta$ of DMF, water and THF are $24.8,47.9$ and $19.5\left(\mathrm{~J} / \mathrm{m}^{3}\right)^{1 / 2}$, respectively. ${ }^{15}$ The calculated solubility parameters of the solvent mixtures with different water content $\left(C_{\mathrm{w}}\right)$ are shown in Table S2.

Table S2. Solubility Parameters $(\delta)$ of Mixture Solvents with Different Water Content $\left(C_{\mathrm{w}}\right)$

\begin{tabular}{cccc}
\hline Solvent & Water content $\left(C_{\mathrm{w}}\right)$ & $\begin{array}{c}\text { Solubility } \\
\text { parameter }(\delta)\end{array}$ & Morphology \\
\hline DMF/water & $10.0 \%$ & 27.1 & spherical polymersomes \\
DMF/water & $12.0 \%$ & 27.6 & spherical polymersomes \\
DMF/water & $36.0 \%$ & 33.1 & spherical polymersomes \\
DMF/water & $50.0 \%$ & 36.4 & spherical polymersomes \\
DMF/water & $66.7 \%$ & 40.2 & spherical polymersomes \\
DMF/water & $95.0 \%$ & 46.7 & dipod and tripod polymersomes \\
DMF/water & $100.0 \%$ & 47.9 & tetrapod polymersomes \\
THF/water & $10.0 \%$ & 22.3 & spherical micelles \\
THF/water & $66.7 \%$ & 38.5 & cylinders with two hollow heads \\
THF/water & $100 \%$ & 47.9 & peapod polymersomes \\
\hline
\end{tabular}




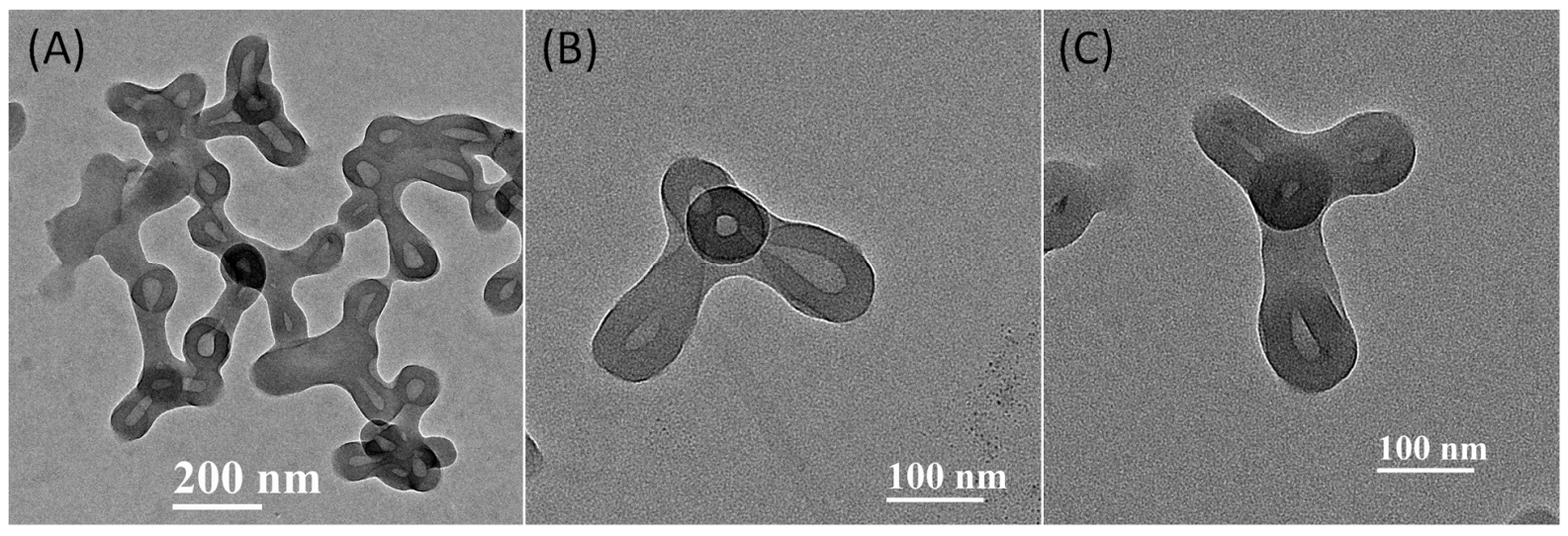

Figure S16. TEM images of tetrapod polymersomes fused by spherical polymersomes that are self-assembled from $\mathrm{PEO}_{113}-b$-P(TBA61-stat-DEA 23$)(\mathrm{P} 3)$ with DMF as organic solvent. The final water content is $100 \%$.

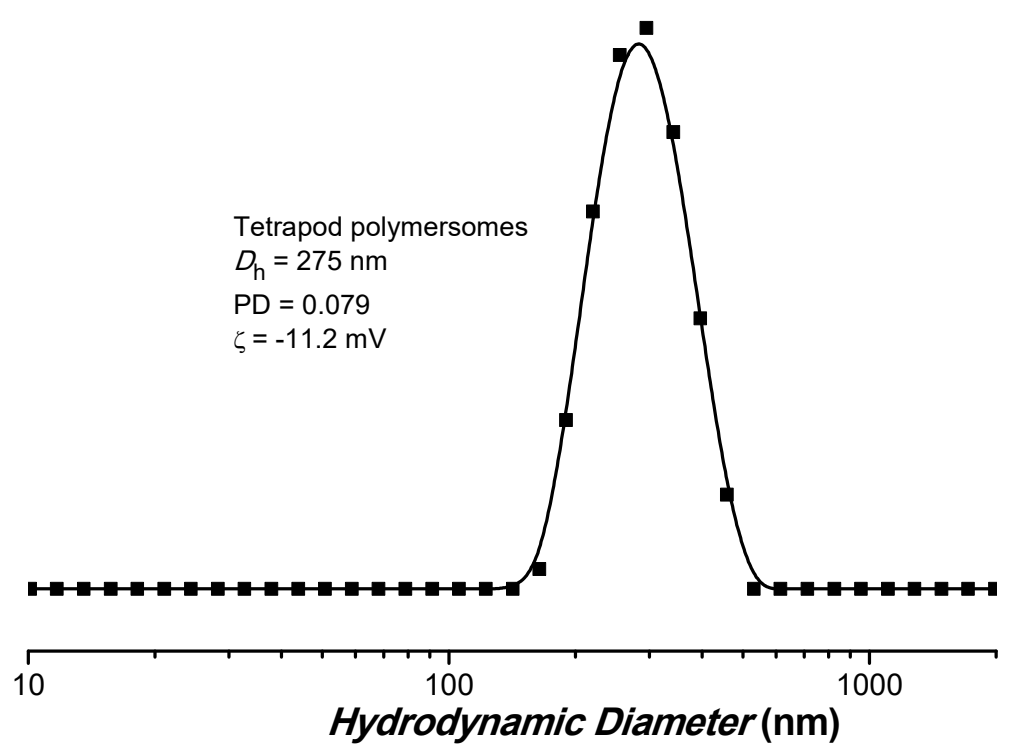

Figure S17. DLS studies of the tetrapod polymersomes fused by spherical polymersomes that are self-assembled from P3 with DMF as organic solvent and a final water content of $100 \%$. 

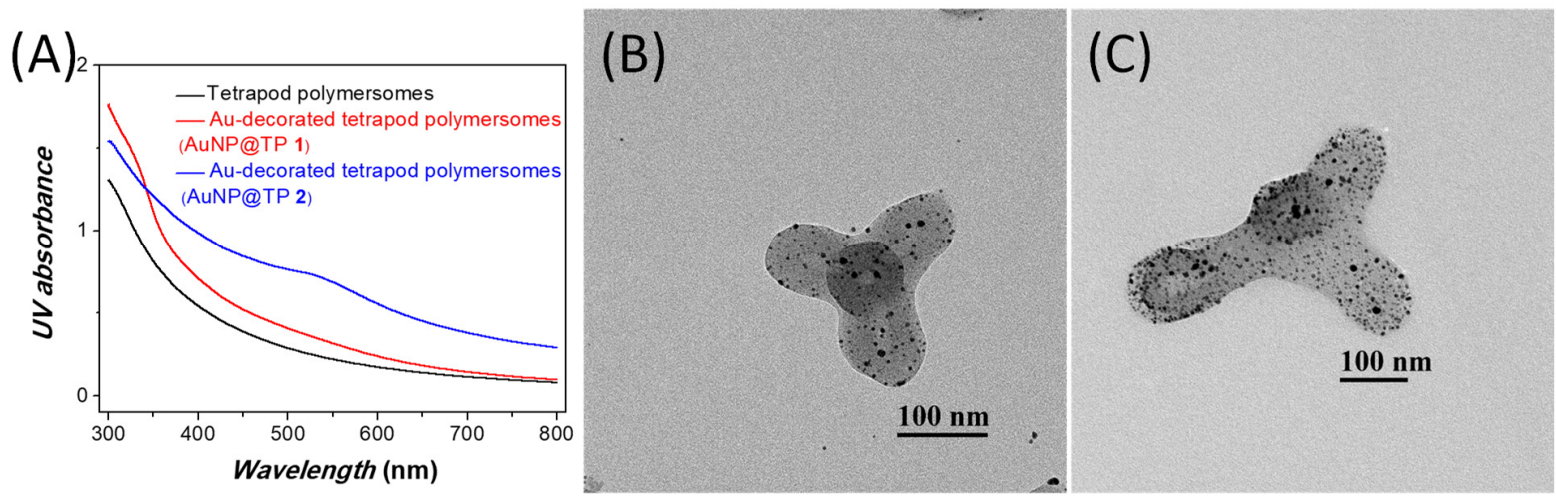

Figure S18. (A) UV-Vis spectra of tetrapod polymersomes, Au-decorated tetrapod polymersomes with an Au:DEA molar ratio of 1:2 (AuNP@TP 1) or 1:1 (AuNP@TP 2); TEM images of (B) AuNP@TP 1 and (C) AuNP@TP 2.

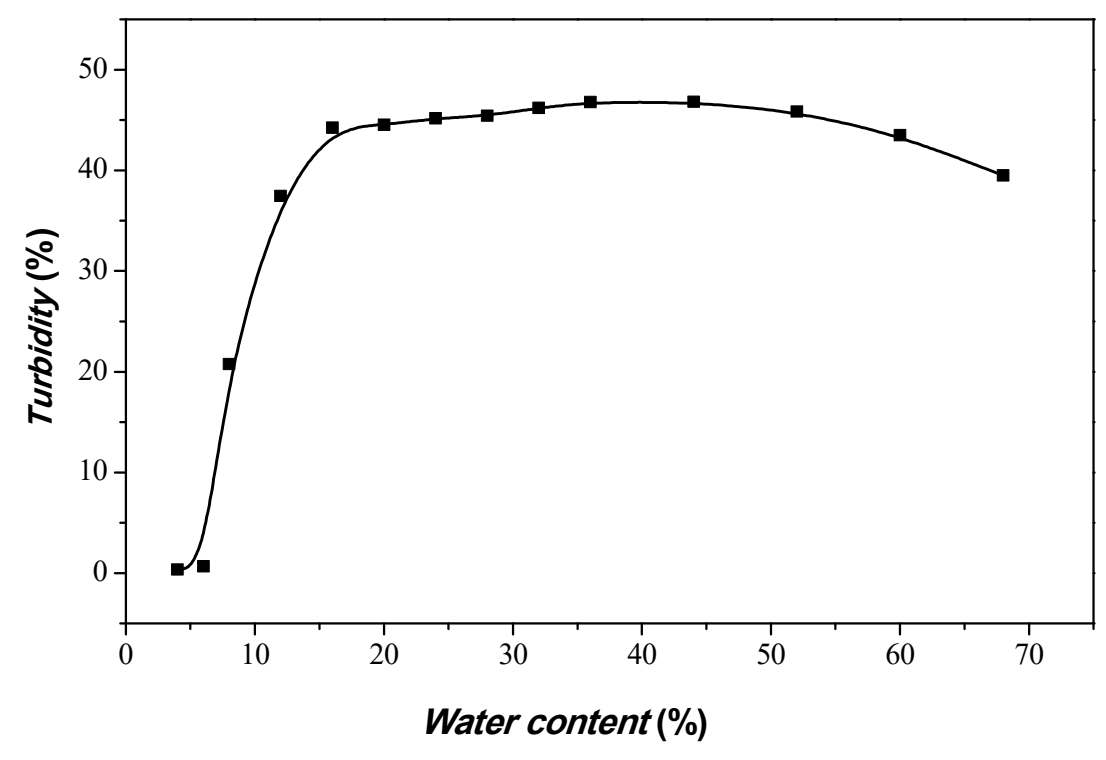

Figure S19. Turbidity measurements of $\mathrm{PEO}_{113}-b-\mathrm{P}\left(\mathrm{TBA}_{61}-\right.$ stat-DEA 23$)$ block copolymer in DMF upon addition of deionized water. The initial copolymer concentration in DMF is $2.0 \mathrm{mg} / \mathrm{mL}$. The decrease in the turbidity after $40 \%$ of water content is due to the dilution effect of the solution. 

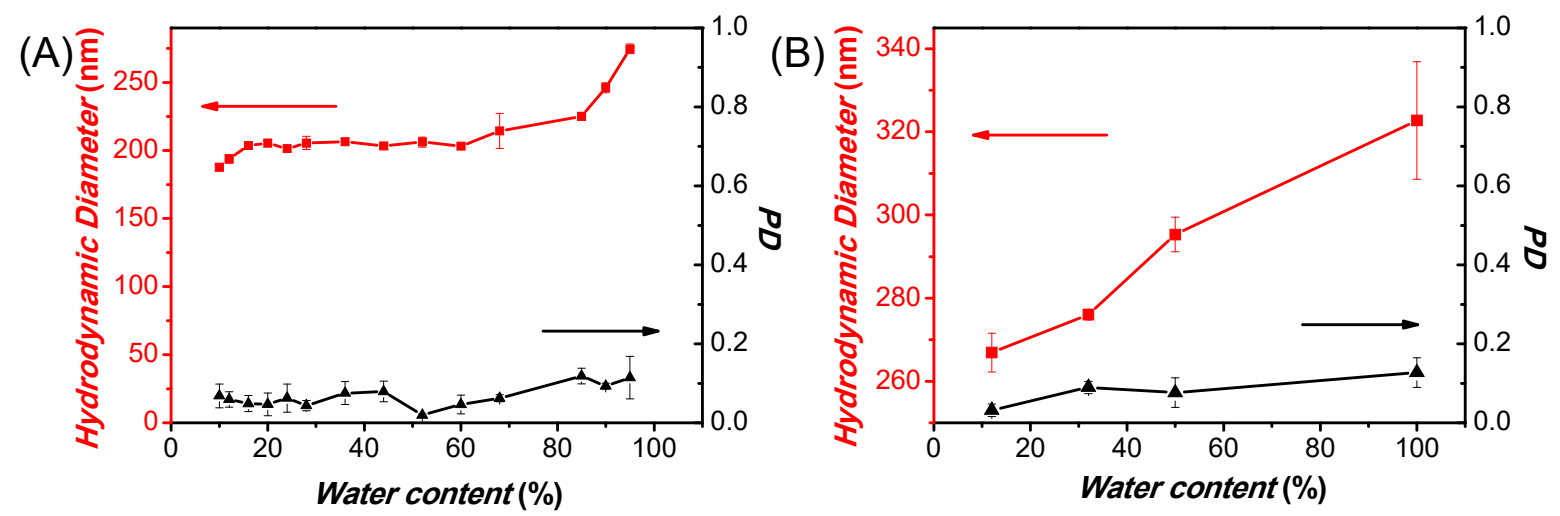

Figure S20. DLS studies during the formation process of $(\mathrm{A})$ the tetrapod polymersomes selfassembled from copolymer P3, and (B) the micelle clusters self-assembled from copolymer P5 with DMF as organic solvent.

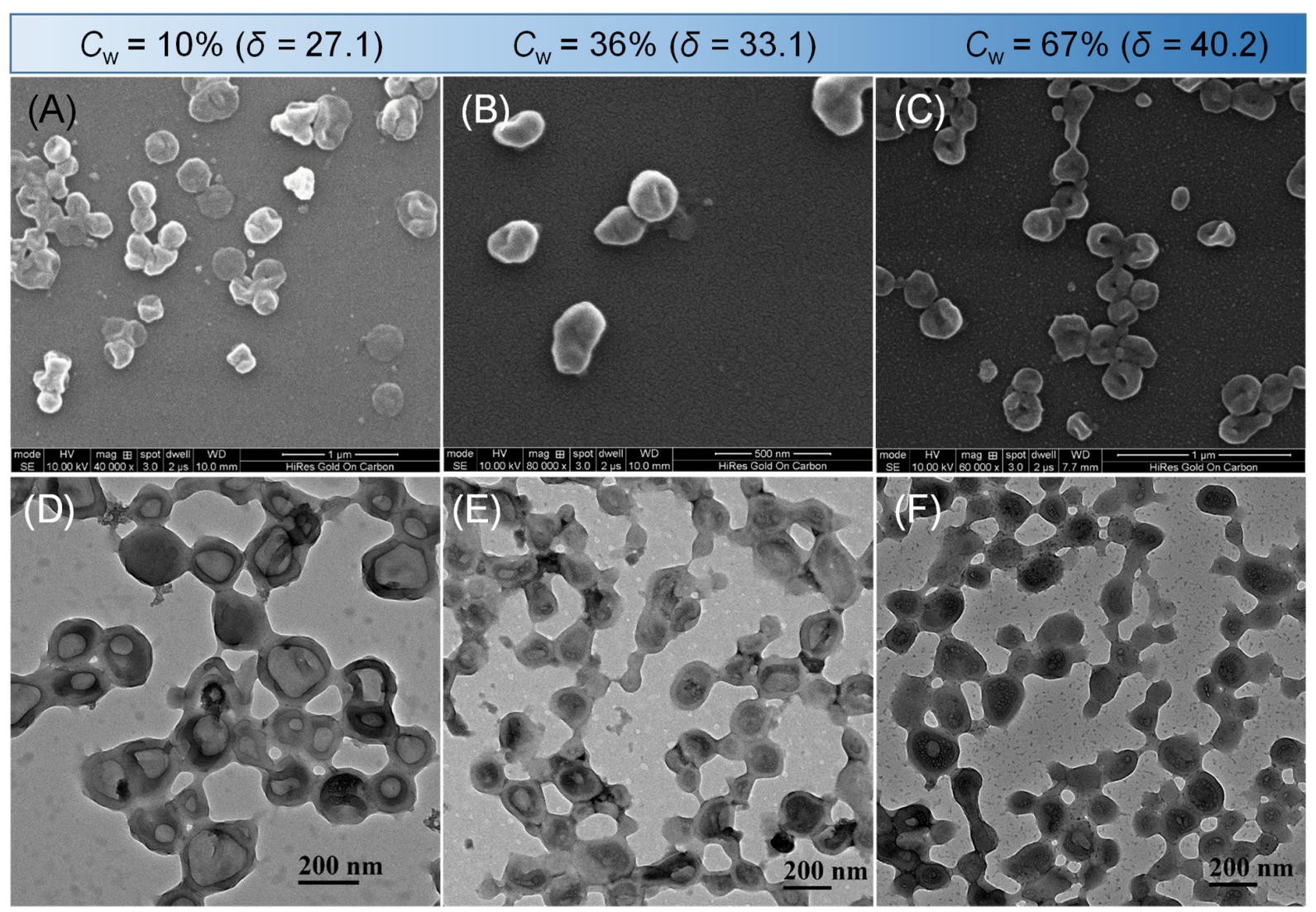

Figure S21. SEM (top) and TEM images (bottom) monitoring the self-assembly process of $\mathrm{PEO}_{113}-b-\mathrm{P}\left(\mathrm{TBA}_{61}-\right.$ stat-DEA 23$)(\mathrm{P} 3)$ at various water content: $(\mathrm{A}, \mathrm{D}) C_{\mathrm{w}}=10 \%$; (B, E) $C_{\mathrm{w}}=36 \%$; (C, F) $C_{\mathrm{w}}=67 \%$. All particles were prepared from polymer solution in DMF. 


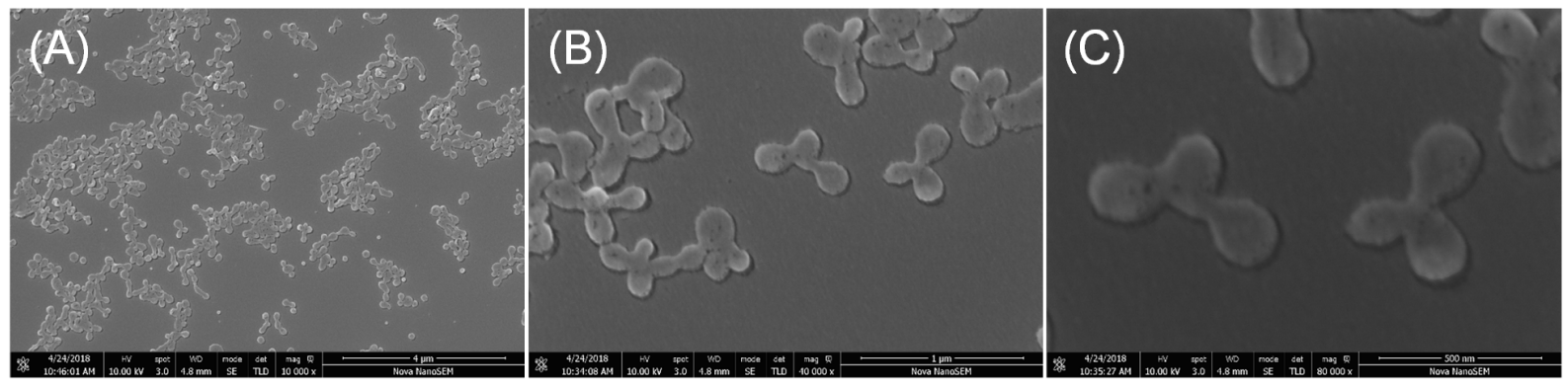

Figure S22. SEM images of tripod polymersomes from $\mathrm{PEO}_{113}-b-\mathrm{P}\left(\mathrm{TBA}_{61}-\right.$ stat-DEA$\left._{23}\right)\left(\mathrm{P} 3, C_{\text {ini }}\right.$ $=2.0 \mathrm{mg} / \mathrm{mL})$ with DMF as organic solvent at $C_{\mathrm{w}}=95 \%(\delta=46.7)$. The scale bars correspond to: (A) $4 \mu \mathrm{m}$, (B) $1 \mu \mathrm{m}$ and (C) $500 \mathrm{~nm}$.

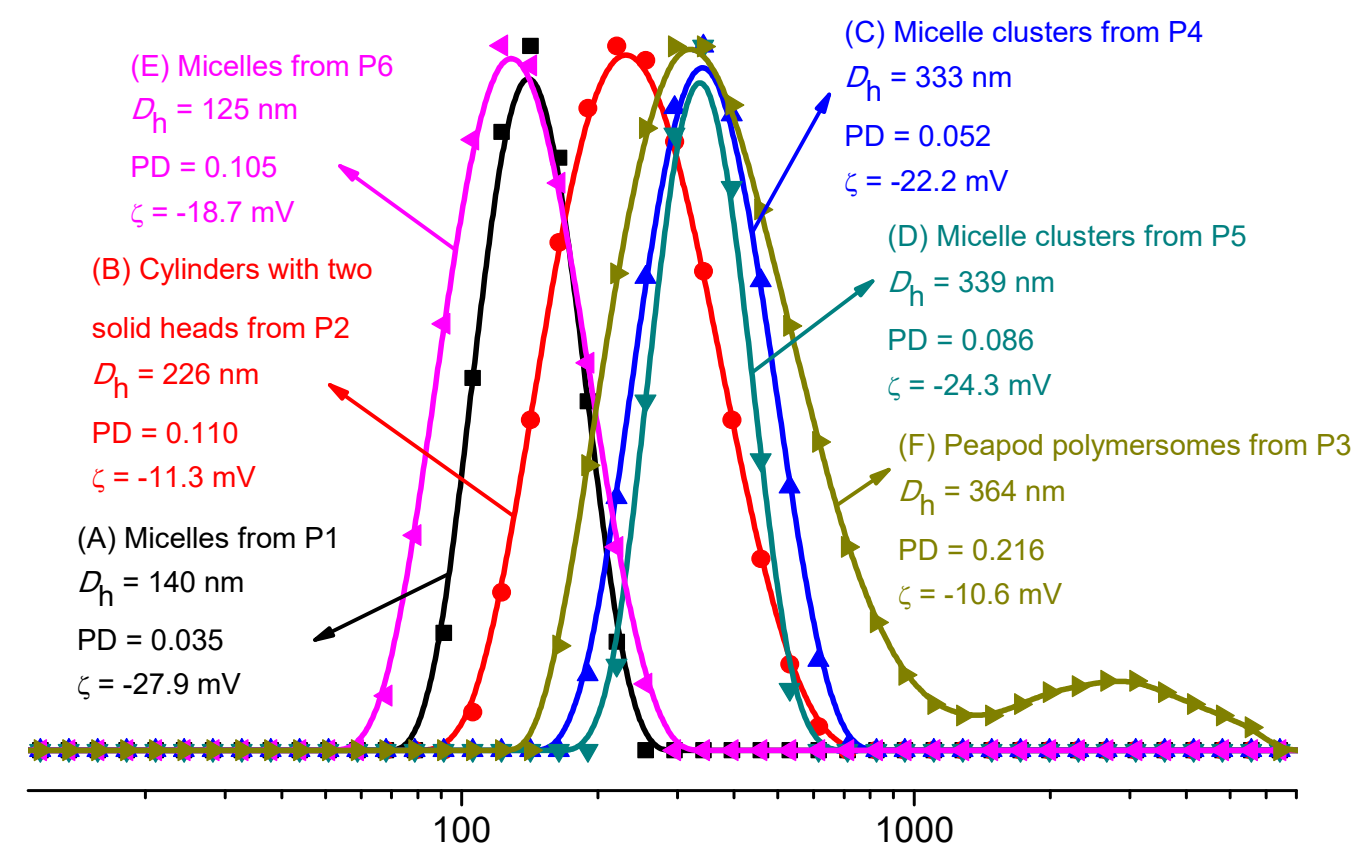

Hydrodynamic Diameter $(\mathrm{nm})$

Figure S23. Normalized DLS patterns of (A) micelles self-assembled from P1; (B) cylinders with two solid heads self-assembled from P2; (C) micelle clusters self-assembled from P4; (D) micelle clusters self-assembled from P5; (E) micelles self-assembled from P6 with DMF as organic solvent and $(\mathrm{F})$ peapod polymersomes from $\mathrm{P} 3$ prepared from THF solution. 


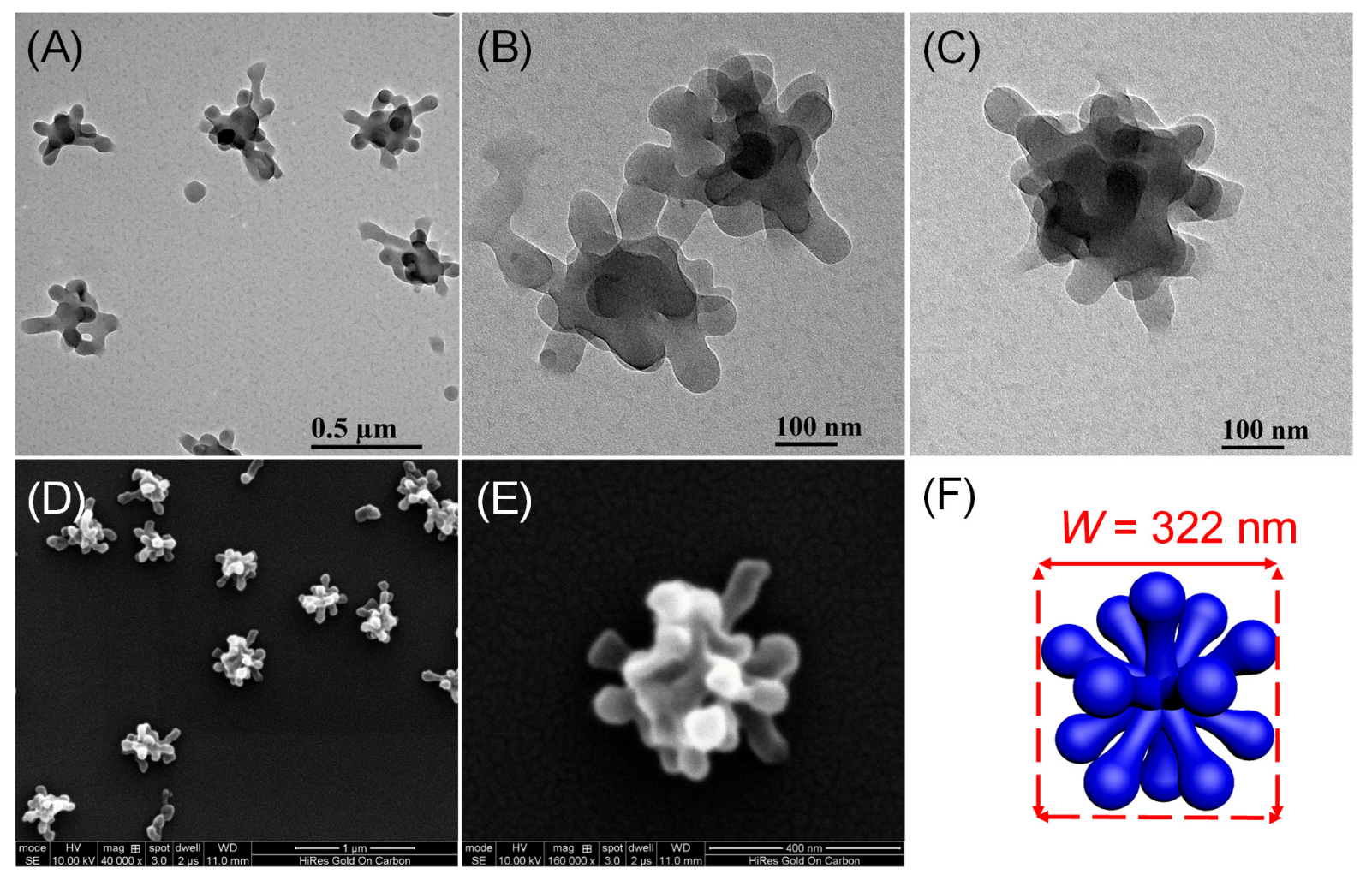

Figure S24. TEM and SEM images of micelle clusters self-assembled from PEO113- $b$-PTBA80 (P5) with DMF as organic solvent: (A, B, C) TEM images; (D, E) SEM images; (F) Schematic model of a micelle cluster. $W$ represents the average diameter of a micelle cluster.

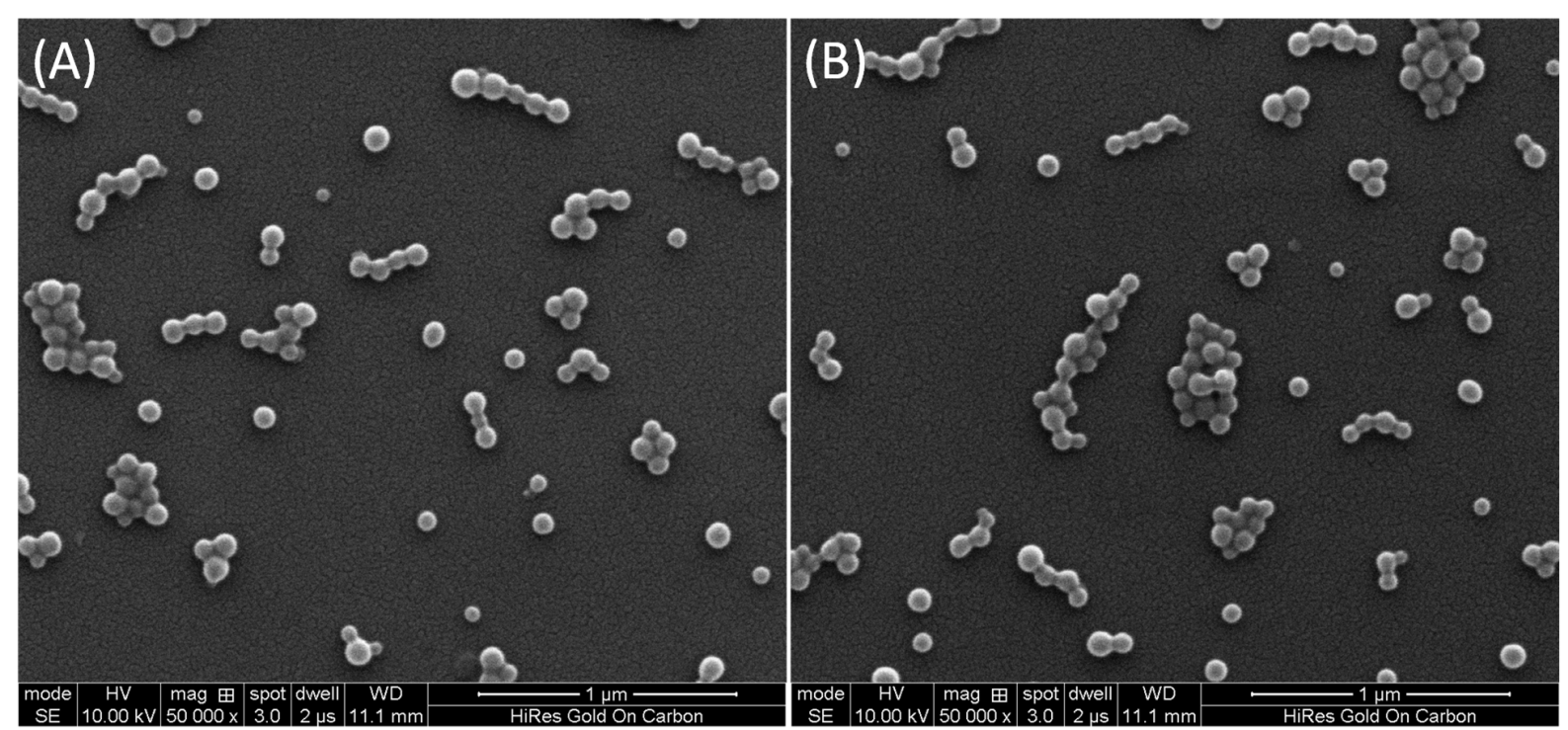

Figure S25. SEM images of spherical PEO113- $b$-PTBEA69 (P6) block copolymer micelles obtained from DMF polymer solutions. 


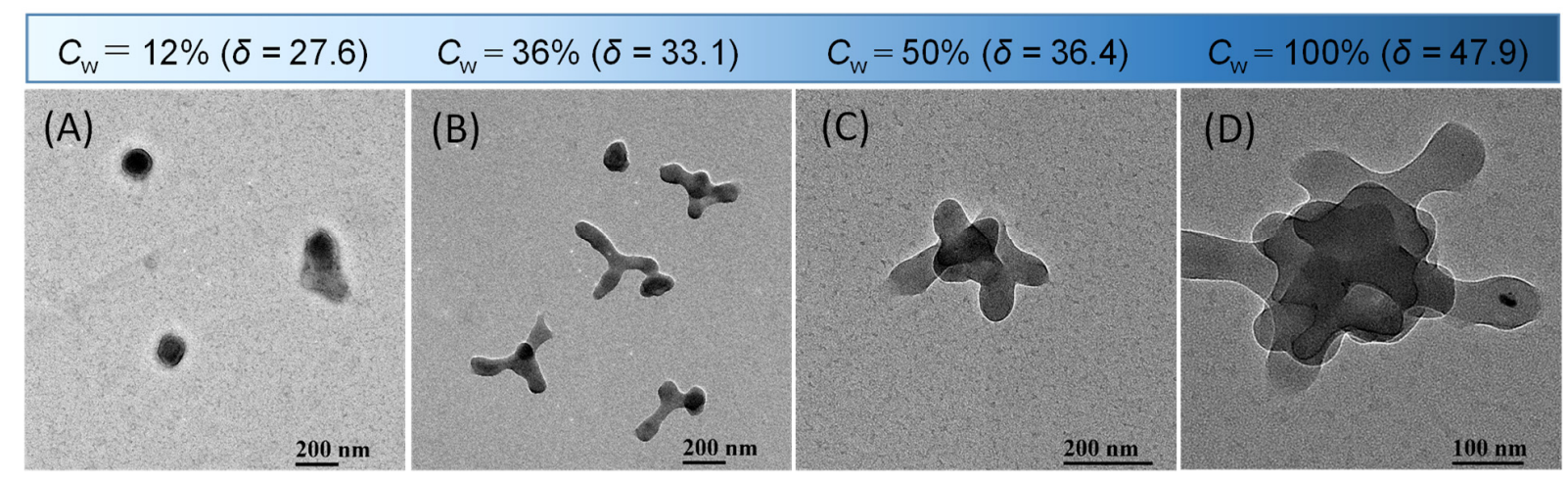

Figure S26. TEM images during the formation process of micelle clusters from $\mathrm{PEO}_{113}-b$-PTBA 80 $\left(\mathrm{P} 5, C_{\text {ini }}=2.0 \mathrm{mg} / \mathrm{mL}\right.$ ) (a similar fusion mechanism to the tetrapod polymersomes from $\mathrm{P} 3$ with DMF as organic solvent was observed). On the top are the $C_{\mathrm{w}}$ and the corresponding solubility parameter $(\delta)$ of the solvent stated.

(A)

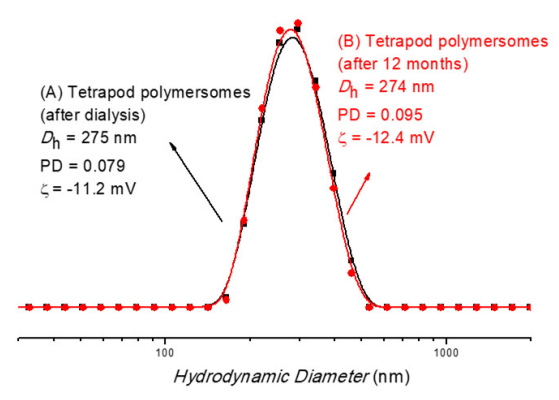

(D)

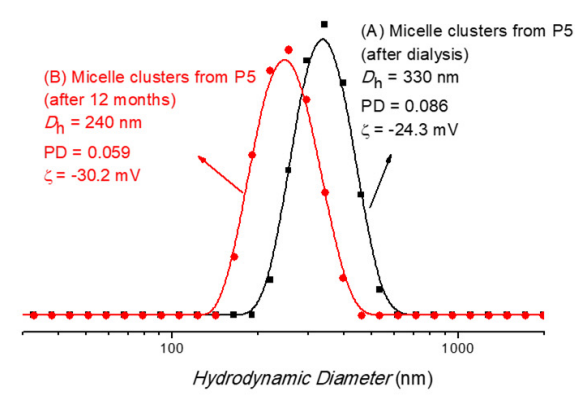

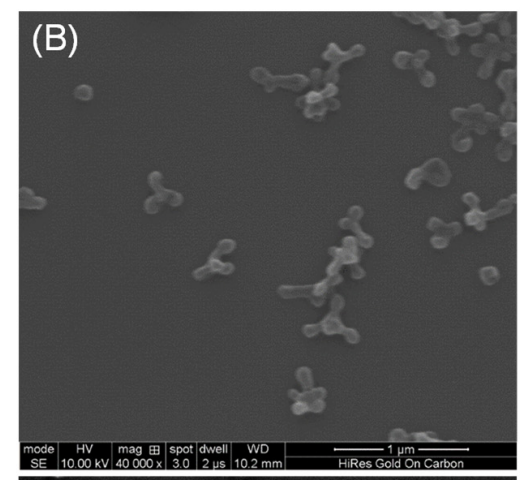
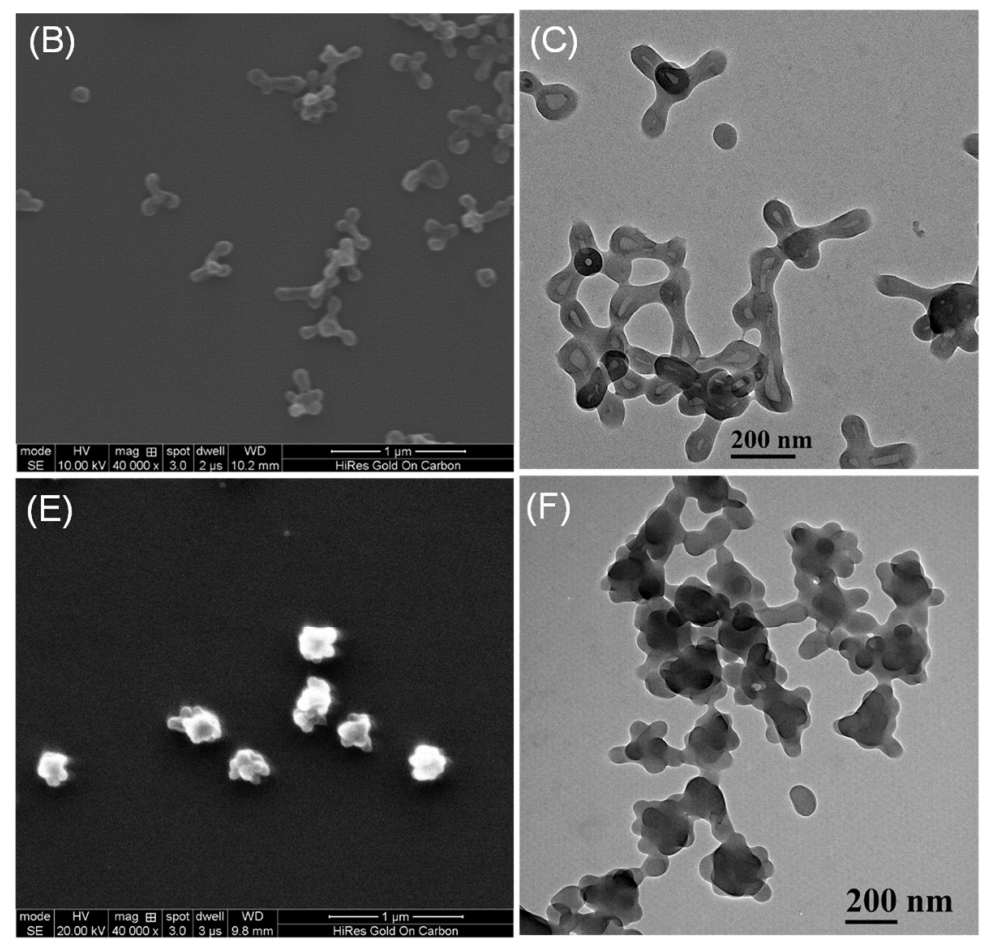

Figure S27. One year aging experiments: DLS, SEM and TEM study of tetrapod polymersomes from P3 (A, B, C) and micelle clusters from P5 (D, E, F) with DMF as organic solvent after one year. Tetrapod polymersomes keep the same morphology while micelle clusters become smaller. 
(A)
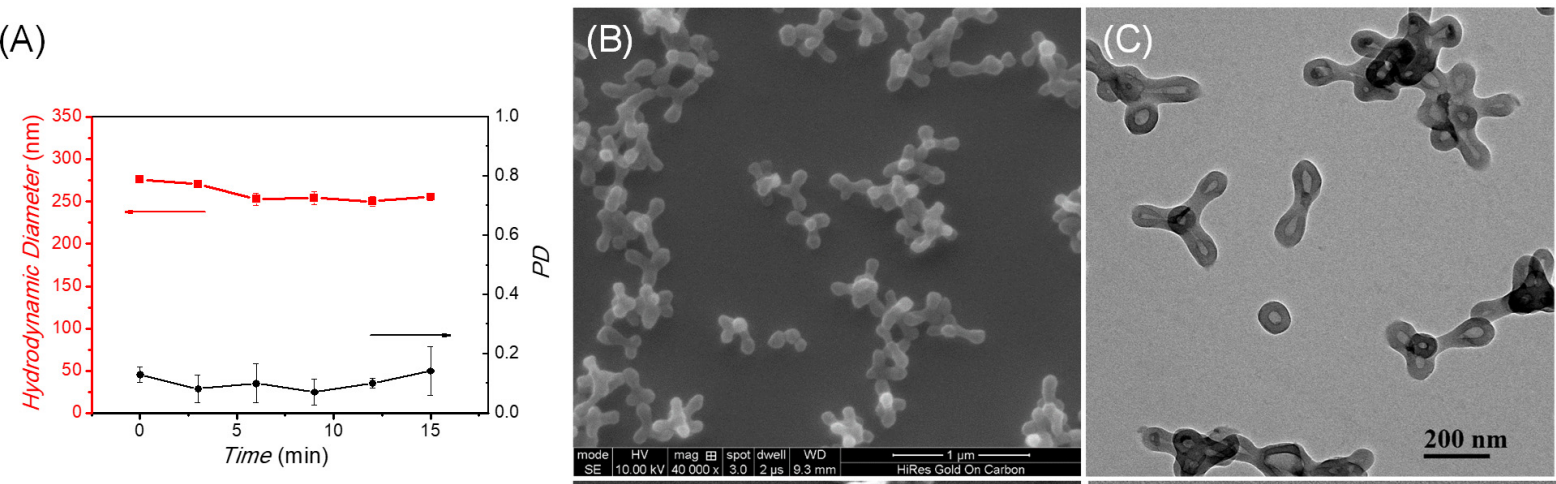

(D)
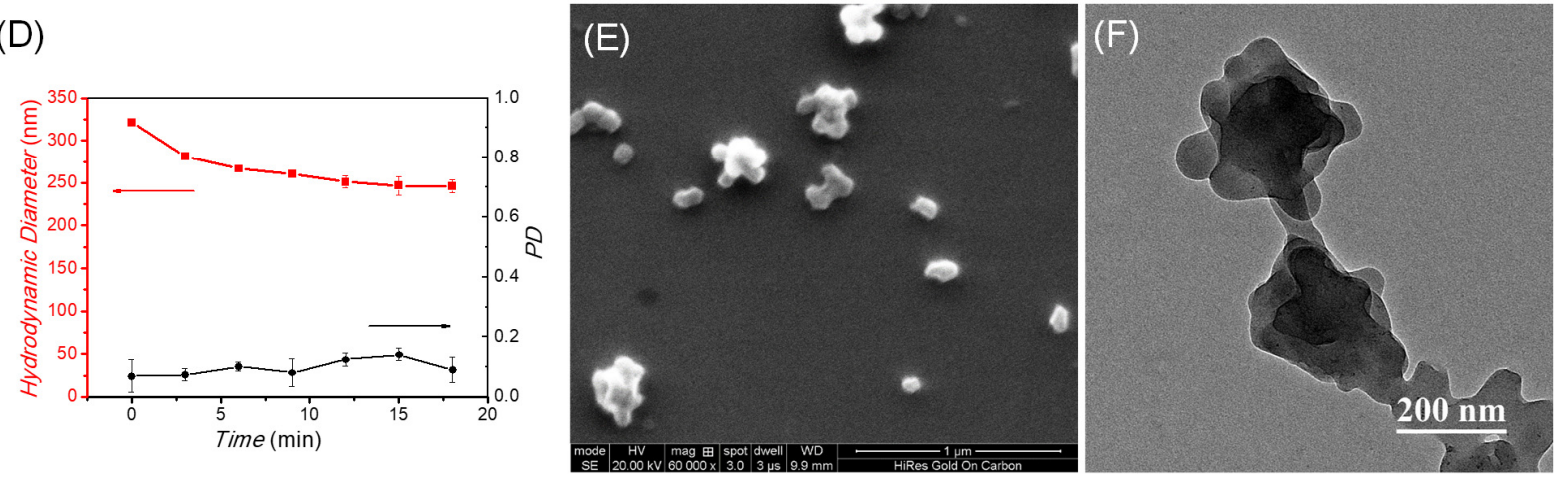

Figure S28. DLS, SEM and TEM studies of micelle clusters from P5 (A, B, C) and tetrapod polymersomes from P3 (D, E, F) with DMF as organic solvent after sonication for $15 \mathrm{~min}$. Micelle clusters become smaller while tetrapod polymersomes keep the same morphology. 
(A)

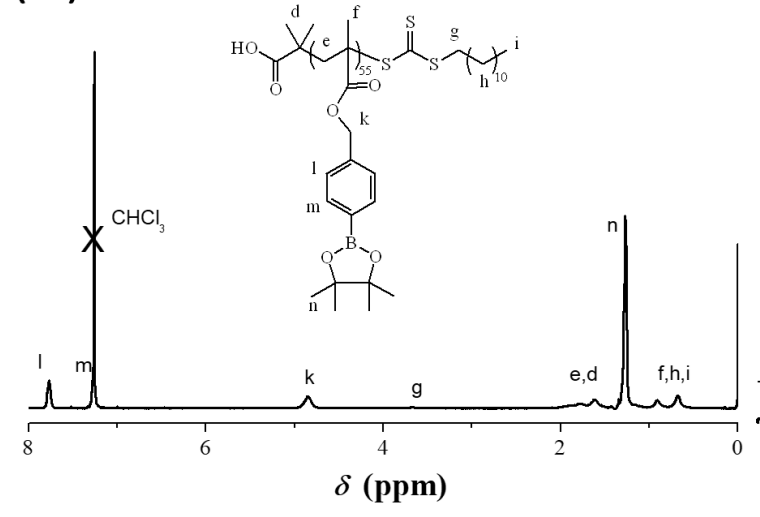

(C) Sample: DSC Size: $2.6000 \mathrm{mg}$

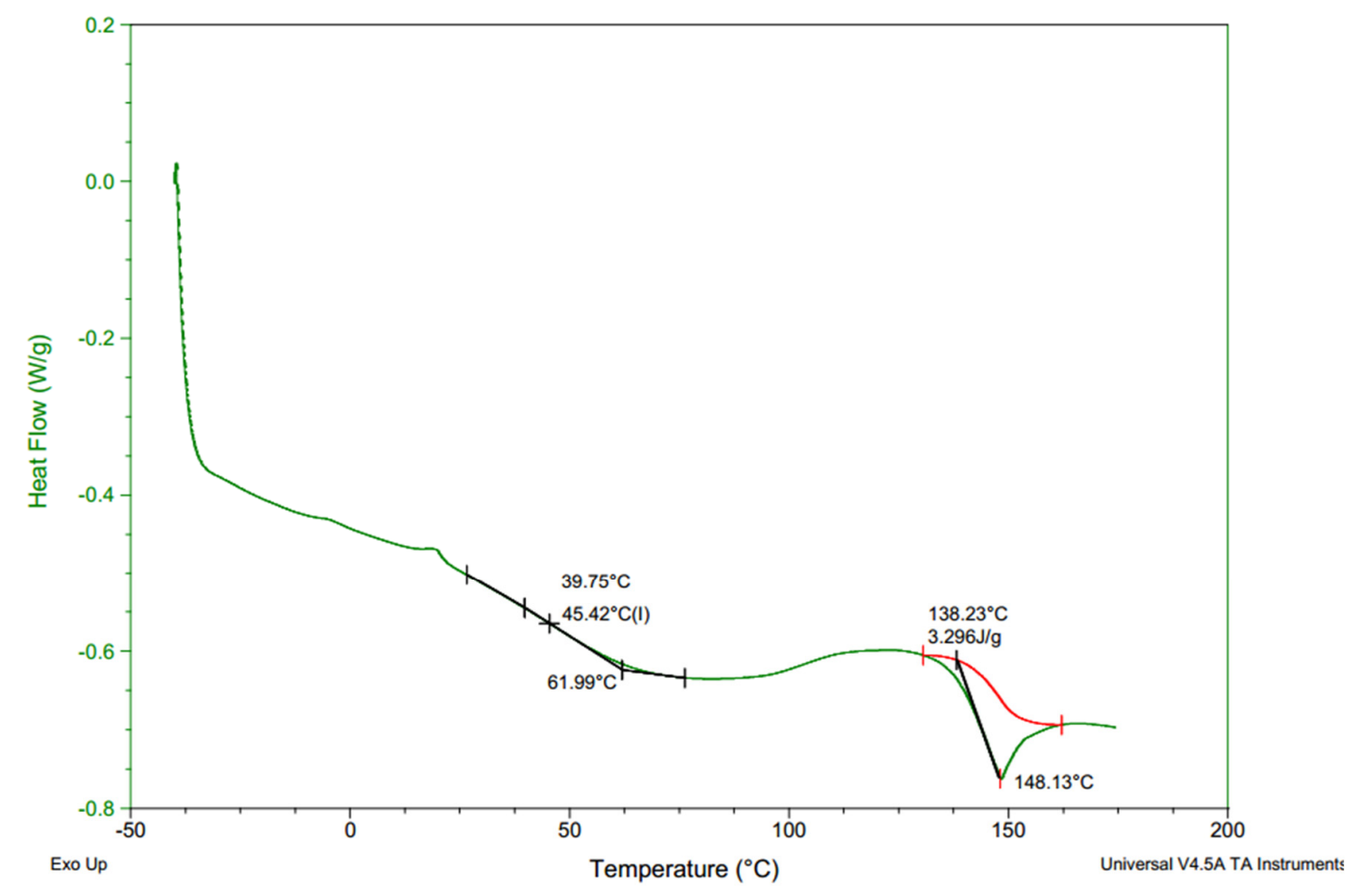

(B)

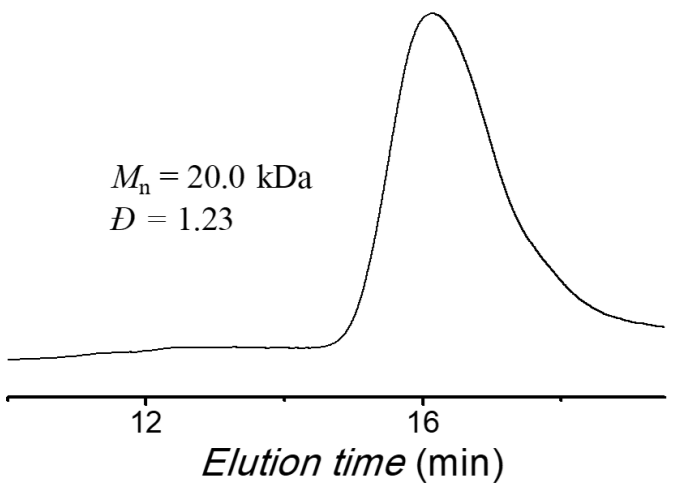

DSC

File: D:...Liaojiangangl2019.9.16xjg|TBA-2

Run Date: 16-Sep-2019 11:20

Instrument: DSC Q100 V9.9 Build 303

Figure S29. (A) ${ }^{1} \mathrm{H}$ NMR spectrum, (B) SEC analysis and (C) DSC analysis of homopolymer PTBA55. 

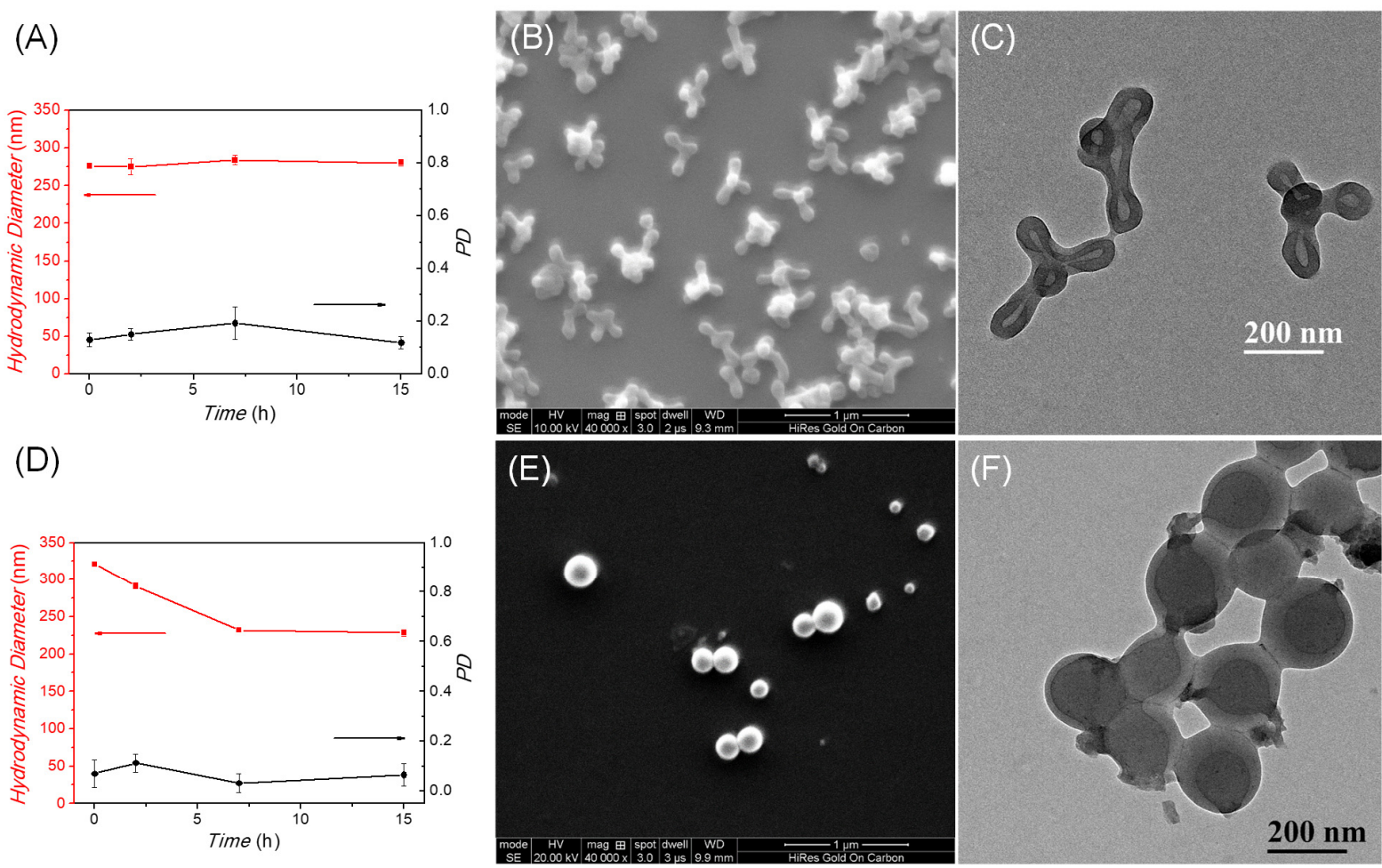

Figure S30. DLS, SEM and TEM studies of micelle clusters from P5 (A, B, C) and tetrapod polymersomes from $\mathrm{P} 3(\mathrm{D}, \mathrm{E}, \mathrm{F})$ with $\mathrm{DMF}$ as organic solvent after thermal annealing at $70{ }^{\circ} \mathrm{C}$ for $15 \mathrm{~h}$. Micelle clusters become spherical morphology with smaller size, while tetrapod polymersomes keep the same morphology and size.

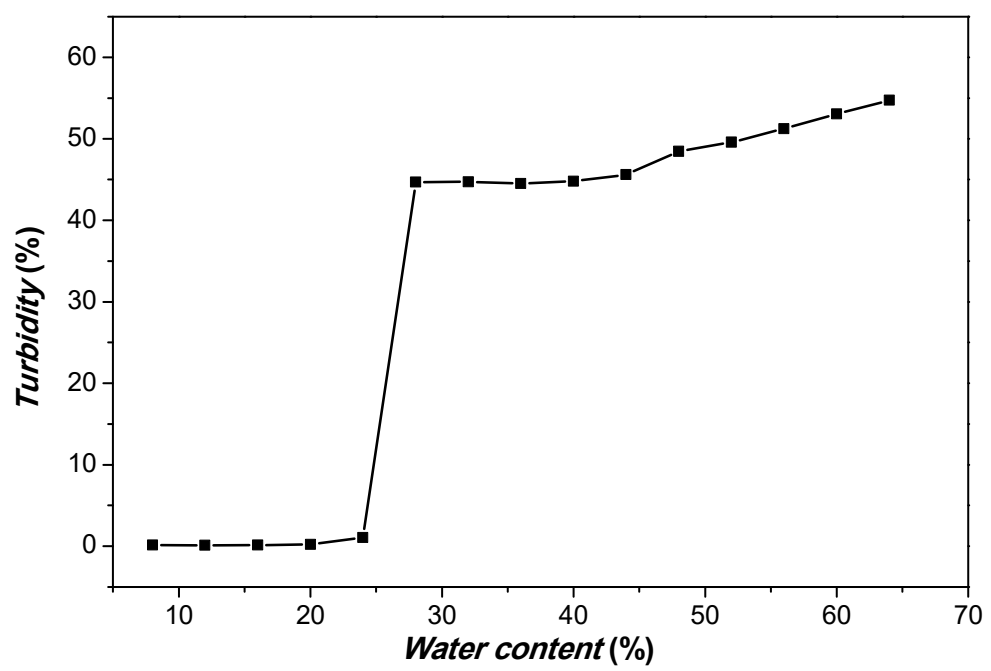

Figure S31. The turbidity studies of $\mathrm{PEO}_{113}-b-\mathrm{P}\left(\mathrm{TBA}_{61}-\right.$ stat-DEA23) (P3) in THF against deionized water. The initial copolymer concentration in THF is $2.0 \mathrm{mg} / \mathrm{mL}$. 


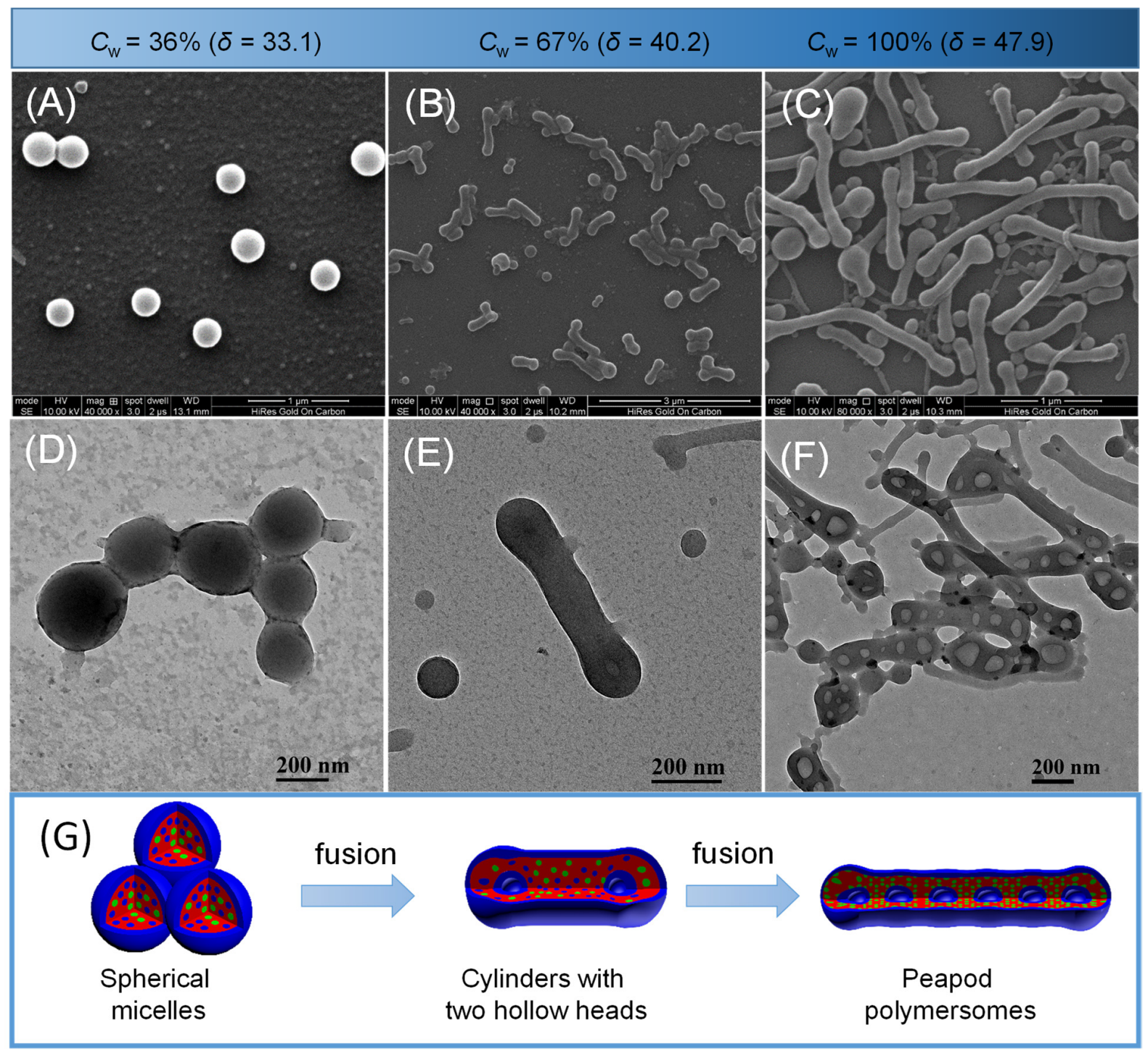

Figure S32. Evolution of peapod polymersomes from $\mathrm{PEO}_{113}-b-\mathrm{P}(\mathrm{TBA} 61-$ stat $-\mathrm{DEA} 23)\left(\mathrm{P} 3 ; C_{\text {ini }}=\right.$ $2.0 \mathrm{mg} / \mathrm{mL}$ in THF; A, C, E: TEM images; B, D, F: SEM images): (A, D) Spherical complex micelles at $C_{\mathrm{w}}$ of $36 \%$; (B, E) Cylinders with two hollow heads at $C_{\mathrm{w}}$ of $67 \%$; (C, F) Peapod polymersomes at $C_{\mathrm{w}}$ of $100 \%$; (G) Illustration of the fusion process. On the top are the $C_{\mathrm{w}}$ and the corresponding solubility parameter $(\delta)$ of the solvent. 


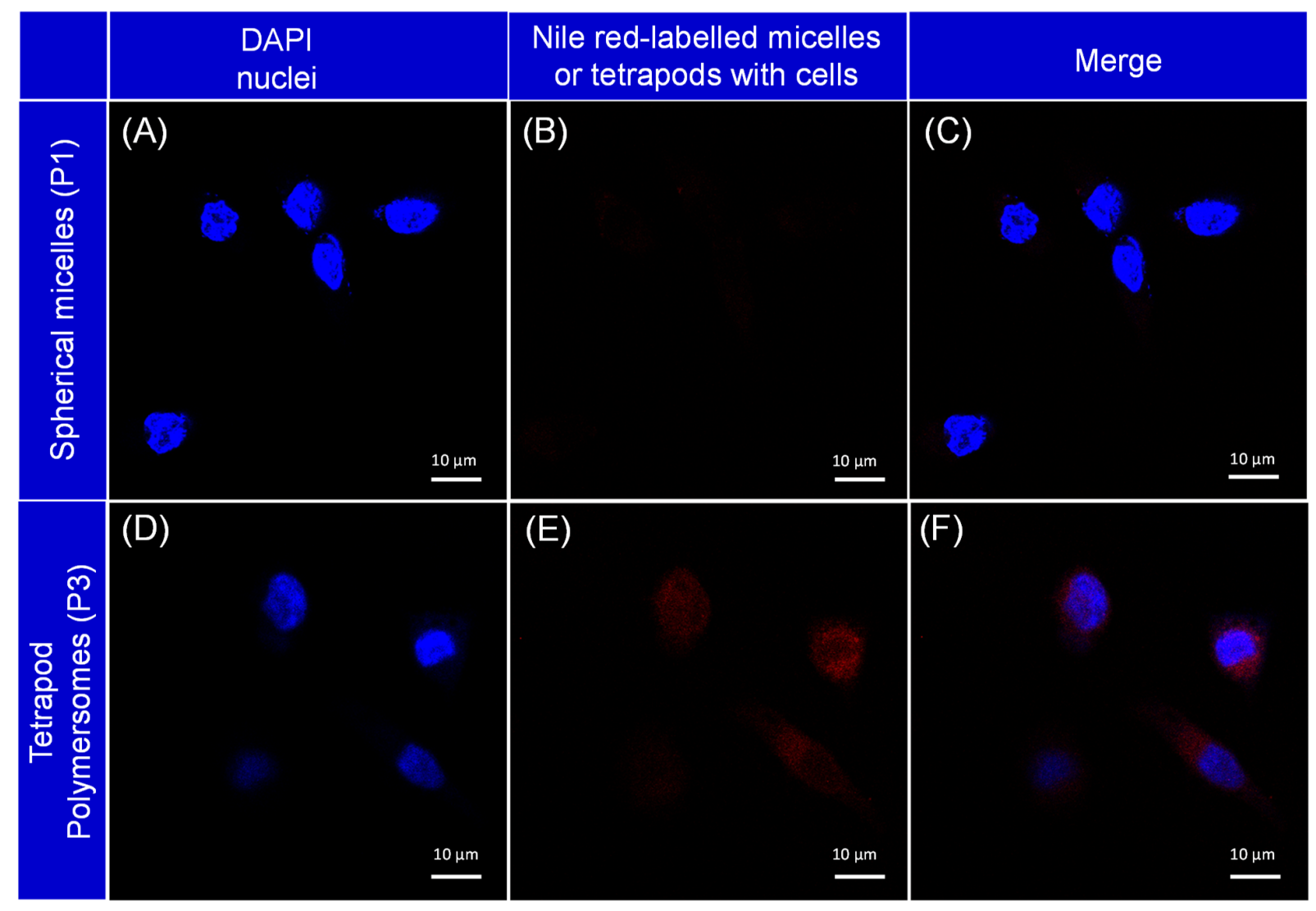

Figure S33. Cellular internalization at $3 \mathrm{~h}$ of $\mathrm{L} 02$ cells incubated with the spherical micelles from $\mathrm{PEO}_{113}-b-\mathrm{PTBA}_{45}(\mathrm{P} 1, \mathrm{~A}-\mathrm{C})$, and tetrapod polymersomes from $\mathrm{PEO}_{113}-b$-P(TBA61-stat-DEA 23$)$ (P3, D-F) labelled with Nile red. (A) and (D) CLSM images of the nuclei stained with DAPI (blue); CLSM images of cells treated with the Nile red-labelled micelles (B) and tetrapod polymersomes (E) (red); (C) and (F) merged images. 


\section{References}

(1) Moore, J. S.; Samuel, S. I. Room Temperature Polyesterification. Macromolecules 1990, 23, 65-70.

(2) Varlas, S.; Keogh, R.; Xie, Y.; Horswell, S. L.; Foster, J. C.; O’Reilly, R. K. PolymerizationInduced Polymersome Fusion. J. Am. Chem. Soc. 2019, 141, 20234-20248.

(3) Gao, L. H.; Lipowsky, R.; Shillcock, J. Tension-Induced Vesicle Fusion: Pathways and Pore Dynamics. Soft Matter 2008, 4, 1208-1214.

(4) Lipowsky, R. Spontaneous Tubulation of Membranes and Vesicles Reveals Membrane Tension Generated by Spontaneous Curvature. Faraday Discuss. 2013, 161, 305-331.

(5) Bermudez, H.; Hammer, D. A.; Discher, D. E. Effect of Bilayer Thickness on Membrane Bending Rigidity. Langmuir 2004, 20, 540-543.

(6) McMahon, H. T.; Boucrot, E. Membrane Curvature at a Glance. J. Cell Sci. 2015, 128, 10651070 .

(7) Lasic, D. D. On the Thermodynamic Stability of Liposomes. J. Colloid Interface Sci. 1990, 140, 302-304.

(8) Lin, Y. L.; Chang, H. Y.; Sheng, Y. J.; Tsao, H. K. The Fusion Mechanism of Small

Polymersomes Formed by Rod-Coil Diblock Copolymers. Soft Matter 2014, 10, 1500-1511.

(9) Gao, L. H.; Shillcock, J.; Lipowsky, R. Improved Dissipative Particle Dynamics Simulations of Lipid Bilayers. J. Chem. Phys. 2007, 126.

(10) Du, J. Z.; Armes, S. P. pH-Responsive Vesicles Based on a Hydrolytically Self-CrossLinkable Copolymer. J. Am. Chem. Soc. 2005, 127, 12800-12801.

(11) Du, J. Z.; Chen, Y. M. Organic-Inorganic Hybrid Nanoparticles with a Complex Hollow Structure. Angew. Chem., Int. Ed. 2004, 43, 5084-5087.

(12) Zhu, Y. Q.; Fan, L.; Yang, B.; Du, J. Z. Multifunctional Homopolymer Vesicles for Facile Immobilization of Gold Nanoparticles and Effective Water Remediation. ACS Nano 2014, 8, 5022-5031.

(13) Sun, H.; Liu, D. Q.; Du, J. Z. Nanobowls with Controlled Openings and Interior Holes Driven by the Synergy of Hydrogen Bonding and Pi-Pi Interaction. Chem. Sci. 2019, 10, 657664.

(14) Lin, Y. L.; Chang, H. Y.; Sheng, Y. J.; Tsao, H. K. Self-Assembled Polymersomes Formed by Symmetric, Asymmetric and Side-Chain-Tethered Coil-Rod-Coil Triblock Copolymers. Soft Matter 2014, 10, 1840-1852.

(15) Hu, Y.; Chen, Y. M.; Du, J. Z. Evolution of Diverse Higher-Order Membrane Structures of Block Copolymer Vesicles. Polym. Chem. 2019, 10, 3020-3029.

(16) Zhu, Y. Q.; Yang, B.; Chen, S.; Du, J. Z. Polymer Vesicles: Mechanism, Preparation, Application, and Responsive Behavior. Prog. Polym. Sci. 2017, 64, 1-22. 